\title{
Predictions of Slat Noise from the 30P30N at High Angles of Attack using Zonal Hybrid RANS-LES
}

\author{
Jeffrey A. Housman, Gerrit-Daniel Stich ${ }^{\dagger}$, Cetin C. Kiris ${ }^{\ddagger}$ \\ NASA Ames Research Center, M/S 258-2, Moffett Field, CA 94035
}

\begin{abstract}
Aeroacoustic predictions of slat noise from the 30P30N three-element high-lift system at high angles of attack are presented using a zonal hybrid RANS-LES method. The simulations are part of the $5^{\text {th }}$ AIAA Benchmark problems for Airframe Noise Computations (BANC-V) Workshop. An economical approach utilizing structured overset grids with spatially varying span-wise grid resolution and a high-order accurate finite difference method is described. The method is utilized for near-field predictions at three angles of attack: $\alpha=5.5,9.5$, and 14.0 degrees. Far-field noise is obtained by propagating the nearfield solution using a permeable surface Ffowcs Williams-Hawkings (FWH) method. Good agreement is obtained with both near-field and far-field Power Spectral Density (PSD) data from an experimental study of the $30 \mathrm{P} 30 \mathrm{~N}$ in the $2 \mathrm{~m} \times 2 \mathrm{~m}$ Kevlar-wall wind tunnel at the Japan Aerospace Exploration Agency (JAXA). ${ }^{1}$ Specifically, the reduction in narrow band peaks and overall broadband noise levels with increasing angle of attack is captured well using the zonal hybrid RANS-LES method.
\end{abstract}

\section{Introduction}

Over the last several decades, propulsion related aircraft noise has decreased, in part from high bypass ratio turbofan engines and nozzle geometry modifications to increase jet shear-layer mixing, as well as improved propulsion/airframe integration. These advancements have increased the relative contribution of airframe noise to the total aircraft noise footprint. The leading-edge slat deployed as part of the high-lift device is one of the major contributors to airframe noise. Broadband noise, generated from the slat leading edge shear layer and its impingement on the lower surface of the slat upstream of the trailing edge, is the primary noise source. ${ }^{2}$ At lower angles of attack, narrow band peaks are observed within the broadband which are caused by a feedback mechanism similar to Rossiter modes observed in cavities. ${ }^{3}$ An additional peak associated with slat trailing edge noise is also observed at higher frequencies correlated to the finitethickness trailing edge. ${ }^{4}$

In an effort to increase the understanding of slat noise generation mechanisms and to mature the prediction capability of high-fidelity numerical simulations, the American Institute of Aeronautics and Astronautics (AIAA) has held a series of workshops for Benchmark problems for Airframe Noise Computations (BANC), which includes Category 7 Slat Noise. ${ }^{5}$ Category 7 investigates the slat noise generated by the 30P30N two-dimensional high-lift model. This configuration has been studied both experimentally ${ }^{6-9}$ and computationally. ${ }^{10-13}$ In previous workshops, BANC-II to BANC-IV, only a relatively low angle of attack case, $\alpha=5.5$ degrees, was investigated. In BANC-V, two additional angles of attack, $\alpha=9.5$ and 14.0 degrees were added to the problem description, in part due to the high quality acoustic data recently obtained in the $2 \mathrm{~m} \times 2 \mathrm{~m}$ Kevlar-wall wind tunnel at the Japan Aerospace Exploration Agency (JAXA). ${ }^{1}$ The authors have been consistent contributors to the workshop since BANC-III, and the Category 7 Slat Noise case has been a driving stimulus to several modeling and simulation enhancements within the Launch Ascent and Vehicle Aerodynamics (LAVA) solver framework. ${ }^{14}$ In addition to the BANC workshop contributions on slat noise, an installed version of the $30 \mathrm{P} 30 \mathrm{~N}$ with a retracted flap which was studied experimentally in the

*Computational Aerosciences Branch, AIAA Senior Member, jeffrey.a.housman@nasa.gov

${ }^{\dagger}$ Science and Technology Corporation, AIAA Member, gerrit-daniel.stich@nasa.gov

${ }^{\ddagger}$ Computational Aerosciences Branch, AIAA Senior Member, cetin.c.kiris@nasa.gov 
open-jet Quiet Flow Facility (QFF) at NASA Langley Research Center ${ }^{15}$ was also analyzed computationally using the LAVA solver. ${ }^{16}$ Comparison of the Power Spectral Density (PSD) spectrum with experimental data showed excellent agreement and three noise source generation areas were identified: the impingement of the slat leading edge wake onto the slat-surface in the cove region, the trailing-edge of the slat, and the trailing-edge of the main-element (note that the flap was stowed in this configuration).

Aeroacoustic predictions of slat noise from the 30P30N three-element high-lift system at high angles of attack are presented using a zonal hybrid RANS-LES method. A description of the BANC-V Category 7 slat noise case is given in Section II. A structured overset grid system with zone dependent span-wise grid resolution is generated for the 30P30N and described in Section III. The zonal hybrid RANS-LES method along with the high-order accurate finite difference method used for the analysis is described in Section IV. Results of the analysis are presented in Section V including the workshop required time-averaged and instantaneous flow-field images and the near-field and far-field PSD comparisons. Section VI summarizes the work.

\section{Problem Description}

The 30P30N geometry is an unswept, 3-element, high-lift configuration designed by McDonnell-Douglas, see Figure 1. It contains a leading edge slat, a main element, and a trailing edge flap, with the slat and flap deflected 30 degrees. The stowed chord of the model is $c=0.457$ meters, the slat chord is approximately 15 percent of the stowed chord $c_{\text {slat }}=0.15 c$, and the flap chord is approximately 30 percent $c_{\text {flap }}=0.3 c$. The baseline Mach number for the workshop is $M=0.17$ with a corresponding chord based Reynolds number of $R e_{c}=1.7$ million. Slight modifications to the slat geometry were made for the BANC series workshops to incorporate unsteady pressure transducers. This required increasing the thickness of the slat trailing edge from zero to $0.76 \mathrm{~mm}$, which introduces a (relatively) high-frequency peak in the PSD spectrum associated with trailing edge noise. The frequency is approximately $452 \mathrm{kHz}$ and is not included in the rangle of PSD spectrums examined in this work. The 2D geometry is modeled with a finite-span of $5.08 \mathrm{~cm}\left(74 \%\right.$ of $\left.c_{\text {slat }}\right)$ as specified in the Category 7 problem statement, with periodic boundary conditions being used in the spanwise direction (Figure 2). This span-length is the minimum length required for span-wise decorrelation of pressure fluctuations determined by the workshop problem leads, Choudhari and Lockard. ${ }^{5}$ Three angles of attack, $\alpha=5.5,9.5$, and 14.0 degrees are considered in the current study, where the higher angles of attack are a new addition to the problem statement in BANC-V.

\section{Structured Overset Grid}

A consistent family of two-dimensional structured overset grid systems were generated around the 30P30N high-lift system consisting of 5 grid zones: the slat, main element, flap, slat cove, and an off-body grid. Figure 3 plots the coarse, medium, fine, and extra fine grids from the family. The grid generation process consists of hyperbolically marching from an initial discretized center-span curve representation of the geometry using a specified wall spacing. O-grids are used for the main-element and flap, but the slat grid has a highly-concave cove region, so the boundaries of the grid in the cove were allowed to splay over each other as well as the solid surface of the slat. In the slat cove region, a specially designed H-grid is generated by hyperbolically marching in both directions from an initial curve which starts at the slat leading edge, continues through the slat cove to intersect tangentially with the slat trailing edge and downstream over the main element until roughly 0.2 chord. Figure 4 shows close-up views of the slat cove mesh for the fine grid. A non-uniform marching distance and initial spacing are used along the length of the initial curve which clusters the grid at the slat leading edge and fans out in the wake of the slat. Once the near-body grids were complete, the off-body grid was generated as a simple stretched Cartesian grid with fine uniform spacing in the region of interest. The grid system was generated using the Chimera Grid Tools ${ }^{17}$ software package version $2.1 \mathrm{p}$ (CGT v2.1p).

Hole-cutting and connectivity were performed by making a minimum hole-cut followed by an automated hole-offset procedure utilizing implicit hole cutting which is part of the pre-processing suite in LAVA. Double fringe layers are enforced throughout all overlap regions to ensure proper communication between grids. The finer grids in the family are generated from the coarse grid by consistently refining in each coordinate direction by a consistent refinement factor. This includes the wall-normal spacing and the transverse shear-layer grid spacing. In addition, the stretching ratio is reduced with grid refinement by $1.25^{1 / r}$, with the refinement 
factors $r=1.0,1.4,2.0$, and 2.6 respectively. Table 1 lists the grid spacing parameters. Steady-state RANS analysis was performed at each angle of attack for the four different grid resolutions and the mesh convergence of the drag coefficient is plotted in Figure 5. From the steady 2D RANS analysis the fine mesh resolution was selected for span-wise grid extrusion and zonal hybrid RANS-LES simulations.

In order predict slat noise on a flight scale full configuration airplane, the modeling and simulation practices developed for two-dimensional configurations must be scrutinized. For example, the high density span-wise mesh distribution used throughout the entire grid system, which is typical for simulating the 30P30N, must only be used judiciously since this is not practical to carry over to a full-scale finite-span wing. As a step towards assessing this methodology, a structured overset grid system was generated for the 30P30N using a zone dependent uniform span-wise grid distribution level which utilizes fine span-wise grid spacing on the zones for the slat and in the slat cove, $N_{\text {span }}=256$, moderate span-wise grid spacing on the zones for the main element and flap, $N_{\text {span }}=128$, and relatively coarse span-wise spacing for the Cartesian off-body grid, $N_{\text {span }}=64$. An illustration of the zone dependent span-wise grid selection is shown in Figure 6. This resulted in a total of 36.7 million grid points for the finite-span three-dimensional grid system. In comparison, Terracol et. al. ${ }^{2}$ used 0.27 million grid points in the two-dimensional plane (almost equivalent to our 0.26 million) and a fixed span-wise resolution of $N_{\text {nspan }}=271$ over the entire solution which resulted in 73.6 million grid points. Therefore the zone dependent span-wise grid resolution is saving roughly half the total number of grid points.

Table 1. Grid spacing parameters (in meters) for the family of two-dimensional 30P30N overset grid systems.

\begin{tabular}{|c|c|c|c|c|c|}
\hline $\mathbf{r}$ & $\mathbf{N}(\mathbf{2 D})$ & $\mathbf{h}(\mathbf{1} / \mathbf{s q r t}(\mathbf{N}))$ & $\mathbf{\Delta} \mathbf{s}_{\text {wall }}$ & $\mathbf{\Delta} \mathbf{s}_{\text {strm }}$ & $\boldsymbol{\Delta} \mathbf{s}_{\text {slat }}$ \\
\hline 1.0 & 68147 & 0.0038 & $3.125 \mathrm{e}-06$ & 0.0050 & $2.00 \mathrm{e}-04$ \\
\hline 1.4 & 128522 & 0.0028 & $2.232 \mathrm{e}-06$ & 0.0036 & $1.43 \mathrm{e}-04$ \\
\hline 2.0 & 258593 & 0.0020 & $1.563 \mathrm{e}-06$ & 0.0025 & $1.00 \mathrm{e}-04$ \\
\hline 2.6 & 434720 & 0.0015 & $1.202 \mathrm{e}-06$ & 0.0019 & $7.69 \mathrm{e}-05$ \\
\hline
\end{tabular}

\section{Computational Methodology}

The LAVA solver framework ${ }^{14}$ is utilized for the computational study. LAVA offers highly flexible meshing options and was developed with the intent of modeling highly complex geometry and flow-fields. The framework supports Cartesian and curvilinear structured grids as well as unstructured arbitrary polyhedral meshes. In this study, the curvilinear structured overlapping grid methodology is applied. Overset grid technology ${ }^{18}$ is used to couple the solutions across different overlapping meshes. The advantage of this approach for aeroacoustic analysis of high-lift systems includes the ability to generate highly anisotropic grids to capture boundary layers, shear layers, and wakes; the high efficiency and low memory footprint of the corresponding numerical algorithm; and the straightforward and inexpensive extension to high-order lowdissipation discretizations which are necessary for capturing flow/acoustic coupling. Allowing the structured grids to overlap each other not only simplifies the process of generating the grids (in comparison to structured multi-block abutting grids), it also allows for high quality (less-skewed) meshes, and an incremental approach to adding anisotropic meshes to better resolve important flow features such as the slat cove region in this particular application. Best practices on overset mesh generation ${ }^{19}$ for subsonic high-lift aircraft ${ }^{20}$ are expanded upon for aeroacoustic analysis of slat noise in this work.

A compressible zonal hybrid Reynolds Averaged Navier-Stokes/Large Eddy Simulation (RANS-LES) model is solved using a finite-difference formulation applied to the non-orthogonal curvilinear transformed system of equations in strong conservation law form. ${ }^{21}$ The Spalart-Allmaras (SA) ${ }^{22}$ turbulence model is used as the base RANS closure model. A zonal approach, denoted Zonal Detached Eddy Simulation (ZDES) model,${ }^{23}$ is utilized to select particular regions of the flow domain to utilize the Detached Eddy Simulation (DES) model, ${ }^{24,25}$ while other regions use the standard RANS model. Details of the turbulence model are given below. Implicit second-order backward differencing is used in physical time and the discretized equations are marched in pseudo-time until a sufficient reduction in the residual has been achieved for each physical time-step (approximately 3 orders of residual reduction is achieved in the present computations). The nonlinear system of equations are linearized at each pseudo-time-step and an alternating line-Jacobi relaxation procedure is applied. Local pseudo time-stepping is used to accelerate convergence with a pseudo- 
time CFL $=10$. Domain decomposition and the Message Passing Interface (MPI) are used to enable a scalable parallel algorithm.

\section{IV.A. Zonal Hybrid RANS-LES model}

The Detached Eddy Simulation ${ }^{24,25}$ (DES) and Delayed Detached Eddy Simulation ${ }^{26-28}$ (DDES) turbulence model closures are well-tested hybrid RANS/LES models for highly separated flows. In the original DES model, the transition between RANS and LES models was based strictly on local mesh size relative to the wall-distance. For geometries with a wide range of geometric length scales, such as a high-lift device with finite-thickness leading and trailing edges, the local mesh spacing may become small enough to force transition from the RANS model to the LES model, but the mesh is typically not fine enough to resolve the unsteady fluctuations near the wall causing depletion of the modeled stress ${ }^{29}$ (incorrect skin friction and potential unphysical flow separation). This brought about the modification of the model denoted DDES which attempts to maintain RANS mode in the attached boundary layer. ${ }^{26}$ Inspection of the switching function often shows a strange behavior of switching from RANS near the wall, to LES, back to RANS just past the edge of the boundary layer, and subsequently back to LES. An alternative strategy appropriate for structured multi-block and overset grids is the Zonal DES (ZDES) approach ${ }^{23}$ in which specific zones are designated to use the RANS, DES, DDES, or LES models explicitly (see Figure 7). This is the approach taken by the present authors for modeling slat noise. The idea of zonal specification has been further generalized to include a user-specified wall distance based transition location between RANS and LES. ${ }^{30,31}$ This allows the user to choose, based on a strong understanding of the physics of the problem, which regions should be solved in pure RANS and hybrid RANS/LES mode. When in hybrid RANS/LES mode it also gives the additional control to the user to prescribe the transition location to explicitly guarantee that the attached boundary layer remains in RANS mode. This is very important since shielding functions, such as those used in the DDES model, can still fail when the mesh is fine enough to capture some three-dimensional fluctuations, but not fine enough to resolve the relevant scales in the boundary layer for accurate prediction of skin friction. For example, when the three-dimension fluctuations from the slat wake merge with the attached boundary layer over the main element, the shielding function can fail to identify this region as an attached boundary layer.

One critique of hybrid RANS/LES models is the slow development of three-dimensional turbulent structures even when the spatial and temporal resolution is more than enough to capture them. This is often caused by the definition of the local length scale in the model, which for the DDES model is the largest edge length associated with the cell (or dual cell) of a grid point. An alternative length scale definition developed using the ZDES approach ${ }^{32}$ utilizes a normalized vorticity vector together with combinations of two-dimensional length scale estimates. The normalized vorticity vector allows the span-wise direction to be identified and removes the grid length spacing in the span-wise direction (which may be large) from the local length scale estimate. This reduction is removed once three-dimensional structures are formed. At this point the normalized vorticity vector will not be aligned with any particular mesh direction and the standard length scale is recovered.

Inspired by a recent extension to ZDES, introduced by Deck et.al. ${ }^{23,33,34}$ and improved by Renard, ${ }^{35}$ in which the model acts in a wall-modeled LES (WMLES) mode (which has also been added to LAVA ${ }^{36}$ ), the authors have also added a Mode 4, which selects the LES length scale regardless of proximity to the wall. This mode is useful for specialized shear layer grids such as the ones used in the slat cove region in this study. A schematic view of the ZDES-Mode selections utilized in the present simulations is shown in Figure 8, where Modes 0 (URANS), 1 (SA-DES97), and 4 (LES) have been chosen. Note that the focus of this study is on slat noise, so by choosing Mode 0 over the main-element and flap, the model allows the user to effectively suppress other potential noise sources while saving total number of grid points since coarser span-wise grid resolution can be used for these regions.

\section{IV.A.1. High-Order Finite-Difference Method}

High-order accurate low dissipation finite-difference schemes have been shown to be an effective strategy for turbulence resolving simulations using LAVA. ${ }^{16,37-39}$ A thorough study comparing several high-order finitedifference methods on Cartesian grids within the LAVA framework was reported previously. ${ }^{40}$ Results from

this study indicated that high-order Weighted Essentially Non-Oscillatory (WENO) schemes ${ }^{41}$ performed well in both resolution (Points-Per-Wavelength PPW), shock capturing, and robustness under harsh flow 
conditions. It is difficult to extend standard finite-difference WENO to curvilinear grids, since identical finitedifference operators must be used for both the metric terms and the convective and diffusive derivatives to maintain free-stream. A more natural extension of finite-difference WENO schemes to curvilinear grids are the high-order Weighted Compact Nonlinear Schemes (WCNS). ${ }^{42}$ The WCNS method, applied to the convective fluxes, consists of WENO interpolation (as opposed to reconstruction) of the left and right states to the half grid points, followed by evaluation of the numerical flux at the half points by an approximate (or exact) Riemann solver or flux vector splitting scheme, and concluding with a high-order central finitedifference operator at the grid points which depends on the numerical fluxes at the half points in either an implicit (i.e. compact) or explicit form. When applying finite-difference methods to the curvilinear equations in strong conservation law form, standard WENO finite-difference methods will not satisfy the Geometric Conservation Law (GCL) making it necessary to combine the WENO interpolation with high-order centraldifference operators. It has been shown that free-stream preservation (i.e. the GCL condition) is satisfied up to machine precision provided that identical central difference operators are used for discretizing the metric terms as well as the fluxes. ${ }^{43,44}$ An additional advantage of WCNS over WENO is the ability to use approximate Riemann solvers. Standard finite-difference WENO methods require the use of flux vector splitting methods for numerical flux evaluation. In this work, a modified version of the Roe numerical flux is used. ${ }^{45-47}$

A consequence of using high-order central difference operators applied to numerical fluxes at the half grid points, which depend on high-order WENO interpolation, is the much wider stencil required for the same order of accuracy compared to the standard finite-difference WENO method. To reduce this pathology, high-order central difference operators using a combination of the numerical fluxes at the half grid points and the physical fluxes at the grid points have been developed. ${ }^{48,49}$ This approach, denoted Hybrid Weighted Compact Nonlinear Scheme (HWCNS), allows for up to third/fourth-order accuracy using a five-point stencil by combining blended third- and fourth-order interpolation with a fourth-order hybrid central difference operator. In the current approach, the convective fluxes (and the metric-terms used within) are discretized with the high-order HWCNS, while the viscous fluxes (and the metric terms) are discretized with standard second-order accurate central differencing. A more detailed description is included in Housman et. al. ${ }^{16}$

\section{Results}

Zonal hybrid RANS-LES simulations were performed to investigate slat noise generated by the 30P30N at three angles of attack, $\alpha=5.5,9.5$, and 14.0 degrees. A cost effective approach was used in this study by utilizing zone dependent span-wise grid resolution, and modeling most of the flow-field using unsteady RANS. This zonal approach not only allows significant savings in total number of grid points, but also allows the slat noise generation process to be isolated from other potential noise sources. The authors believe this will be an affordable methodology that can be applied to full aircraft and/or finite-span wing configurations. A time-step of 1 micro-second with 3 sub-iterations using 2 sweeps of alternating line-Jacobi relaxation to approximate the solutions of the linearized systems was used. This resulted in $3-4$ orders of magnitude residual reduction at each physical time-step. This time-step was shown adequate for the LAVA solver in previous BANC workshops.

Visualizations of the instantaneous and time-averaged flow-field quantities are analyzed, and qualitative flow behavior changes with respect to angle of attack are discussed. In order to assess the validity of the zonal approach, near-field and far-field PSD comparisons with available experimental data and previous workshop results are made. In addition, the CFD data is also analyzed alone to assess the effects on the PSD spectra with increasing angle of attack.

\section{V.A. Flow-Field Visualization}

Simulating aeroacoustic phenomenon requires high-resolution schemes which can accurately predict the acoustic generation mechanisms (i.e. low-dissipation), as well as capture linear and nonlinear wave propagation (i.e. preserving the physical dispersion relation). An illustration of the high-resolution capability of the high-order finite difference scheme used in this study is shown in Figures 9 (a)-(c), which plots an iso-contour of $x$-vorticity colored by normalized velocity (left) and the density gradient magnitude (right) for each angle of attack. The iso-contour of $x$-vorticity shows the three-dimensional turbulent structures generated at the slat leading edge which convect into the slat cove and impinge on the lower surface of the 
slat upstream of the trailing edge. A portion of this shear layer becomes trapped in the slat cove creating a low-speed turbulent recirculation bubble, while the other portion gets ejected through the slat gap and merges with the slat trailing edge shear layer convecting over the main-element. The size of the recirculation bubble in the slat cove is reduced with increasing angle of attack due to the shear-layer impingement location traveling upstream on the lower surface of the slat. This feature will be more obvious when looking at the time-averaged flow-field data. Examining the density gradient magnitude, specifically the brown and dark red contour levels below the main element, a noticeable shift in the acoustic wave directivity is observed relative to the main element. As the angle of attack is increased, the directivity shifts from roughly 300 degrees at $\alpha=5.5$ degrees to 340 degrees at $\alpha=14.0$ degrees in the aircraft reference frame. Farfield directivity plots will be analyzed in the final results section to determine the quantitative dependence of the sound propagation to angle of attack changes.

A comparison of the instantaneous (left) and time-averaged (right) span-wise vorticity contours for each angle of attack is shown in Figure 10. The strong unsteady nature of the shear-layer impingement region is illustrated by the large magnitude instantaneous span-wise vorticity contours being significantly reduced in magnitude once time-averaging is applied. The time-averaged span-wise vorticity also clearly shows the upstream shift in the shear-layer impingement location with increasing angle of attack. This upstream shift is further illustrated in the time-averaged two-dimensional velocity magnitude plots shown in Figure 11 (left). In addition, the two-dimensional turbulent kinetic energy (TKE2D) is plotted in Figure 11 (right) where an interesting phenomenon is observed. The $\alpha=5.5$ degree case is typical of previous workshop participant results with a short delay in TKE onset from the initially laminar slat leading edge shear layer, then a small peak just downstream of the onset, followed by a decrease in level until the shear-layer impingement region is encountered. At the saturated levels plotted, the impingement region and slat trailing edge shear-layer regions are merged and can't be distinguished from each other. As the angle of attack is increased there is a noticeable delay in the development of TKE and a clear distinction between the impingement region and the trailing edge region. This may provide some basic understanding of the shift in acoustic wave directivity that was observed in the magnitude of the density gradient plots. More over, this suggests that the slat leading edge shear-layer remains laminar for a longer extent as the angle of attack increases (at least at this relatively low Reynolds number).

\section{V.B. Near-Field Power Spectral Density}

Several numerical sensors were included in the zonal hybrid RANS-LES simulations, a diagram of the sensor locations is shown in Figure 12 (a). At the baseline angle of attack, $\alpha=5.5$ degrees, the PSD at sensor locations 1, 4, and 6 are plotted against both the experimental (symbols), and previous workshop participants (lines) from Choudhari and Lockard ${ }^{5}$ in Figure 12 (b)-(d). The results for the present simulation are plotted over using a thick black line. Sensor location 1 was identified as a sensitive location in previous workshops, where a bifurcation in the results is observed. Our current simulations appear to fall on the upper branch of this bifurcation which is consistent with our previous workshop result. We are BANC-III participant 13 (fine-grid) and 14 (coarse-grid) in these plots. A tighter band is observed at sensor location 4, and the current result falls within the upper portion of this band (following the JAXA LWT2 solid wall wind tunnel results). Location 6 is another previously identified sensor location which contains low enough broad-band noise levels that narrow-band peaks can be observed in the spectra. Our current results match the lowfrequency broad-band noise levels of BANC-III participant 15 (Exa-Powerflow) and the narrow band peaks observed in the experimental spectra of BANC-III participants 00 (FSU WT) and 01 (JAXA LWT2). At higher frequencies, the broad-band levels of the current results begin to follow the experimental results. A spurious tone is also observed in our PSD spectra at $6785 \mathrm{~Hz}$. This frequency exactly corresponds to an acoustic wave length equal to the $0.0508 \mathrm{~m}$ span we are using. This spurious tone was also observed using OVERFLOW as reported in Lockard et. al., ${ }^{12}$ they were able to remove this tone by modeling a much larger span with symmetry plane boundary conditions used on the side-walls, while aggressively coarsening in the span-wise direction to not add a significant amount of grid points. Since the problem description for the workshop specifies the baseline span-wise extent and use of periodic boundary conditions in the span-wise direction, a vertical line indicating the spurious tone will be added to spectral plots when appropriate.

Good agreement in the near-field PSD predictions at $\alpha=5.5$ degrees with BANC-III workshop results also carries over at the larger angles of attack when comparing to the more recent $2 \mathrm{~m} \times 2 \mathrm{~m}$ Kevlar-wall JAXA wind tunnel results. ${ }^{1}$ Figures 13, 14, 15, and 16 plot the near-field PSD spectrum from the current simulations along with JAXA wind tunnel results at four distinct sensor locations and all three-angles of 
attack. Note comparisons with wind tunnel data include two bounding angles of attack to account for the expected shift in lift coefficient with angle of attack caused by severe blockage effects in the wind-tunnel. The angle of attack shift developed in $^{1}$ from comparing the lift coefficient measured in the wind tunnel test to free-air steady-state RANS simulations is used in the current comparison, so minor discrepancies are to be expected. The broad-band noise levels at sensors 4 and 5, near the slat trailing edge, exhibit two trends. The first trend is that the zonal hybrid RANS-LES method predicts the low frequency spectrum (below $1 \mathrm{kHz}$ ) within approximately 1-2 $\mathrm{dB}$. The second observation is that the method overpredicts the broadband levels by 3-6 $\mathrm{dB}$ for frequencies between 1 and $10 \mathrm{kHz}$ depending on the angle of attack being compared. Note that some of this over-prediction is caused by spectral leakage associated with the spurious tone at $6785 \mathrm{~Hz}$. At sensor locations 8 and 9, away from the impingement area, the broad-band levels are significantly lower and narrow band peaks are observed between 1 and $5 \mathrm{kHz}$. The predicted narrow band peaks compare very well in their location and are within 2-3 dB in level with the wind tunnel data. The additional peak observed in the simulation data at $6785 \mathrm{~Hz}$, which has been marked with a vertical black line, is associated with the aforementioned spurious tone. The sharp increase in broadband levels around the spurious tone is also observed, which provides further evidence that this tone is leading to the over-prediction of the broadband levels observed at sensor locations 4 and 5 . As in the $\alpha=5.5$ degree case these spurious peaks are associated with using the span-wise periodic boundary conditions and the associated limited span-wise extend of the computational domain.

In order to assess near-field PSD trends with angle of the attack, the simulated results are isolated and plotted for sensor locations 1, 2, and 6 in Figure 17. Two major effects are observed with increasing angle of attack, which are consistent at all the sensor locations. First, the overall PSD levels decrease across the entire spectrum with increasing angle of attack. This effect is correlated with the reduction in TKE levels and the separation distance of the leading edge slat shear layer impingement location with the slat trailing edge. The second effect is a reduction in the magnitude of the narrow band peaks with increasing angle of attack. The narrow band peaks have been attributed to a feedback mechanism similar to Rossiter modes observed in cavity flows. ${ }^{3}$ In order for the slat cove region to act as an effective cavity, the slat leading edge shear layer must travel across the cove similar to flow over a cavity. Since the shear-layer impingement moves upstream with increasing angle of attack, the flow mimics more of a jet impinging on a flat plate, diminishing the length scale necessary for cavity related narrow band peaks. This is visually demonstrated in Figure 18 and Figure 19 which plots the real-part of the Fourier coefficient of pressure (left) and the PSD (right) at the first $1350 \mathrm{~Hz}$ and second $1900 \mathrm{~Hz}$ narrow band peaks observed in the the near-field PSD spectrum. It is observed that the magnitude of the acoustic pressure reduces significantly with increasing angle of attack for both narrow band peaks. This suggests that the increased separation distance between the slat leading-edge shear layer impingement location and the slat trailing edge with increasing angle of attack makes the interaction less effective at generating acoustic waves at these frequencies.

\section{V.C. Far-Field Power Spectral Density}

Time-accurate volume data from the zonal hybrid RANS-LES simulation was interpolated onto an acoustic surface triangulation (Figure 20) and propagated to the far-field using the permeable surface Ffowcs WilliamsHawkings (FWH) method within LAVA. ${ }^{14}$ The particular formulation of the frequency-domain permeable surface FWH equations used in LAVA is similar to that presented in Lockhard, ${ }^{50}$ which was developed for airframe noise propagation. The formulation is equivalent to the one used by Bres et. al. ${ }^{51,52}$ The one exception is the substitution of the density perturbation with pressure perturbation, $\rho^{\prime}:=\rho_{\infty}+p^{\prime} / c_{\infty}^{2}$, suggested by Spalart et. al. ${ }^{53}$ Construction of the closed FWH surface is based on the outer-mold line of the 30P30N extruded away from the body and expanded in the rear for the wake of the flow. A $0.0254 \mathrm{~m}$ thickness is used, as the experimental results (and requested workshop data) are normalized to 1 inch. The surface contains 136292 triangles and the solution is interpolated to the triangle centroids using the same tri-linear interpolation routines used for the fringe points in the overset solution algorithm. The far-field propagation utilizes 100000 time-steps $\left(100000 \Delta t U_{\text {ref }} / c=12.76\right.$ convective time-units) of the zonal hybrid RANS-LES simulation with a sampling rate of every 5 time-steps. The total time sample is sub-divided into 33 windows (or segments) with 50 percent overlap, where each window has a frequency resolution of $\Delta F_{\text {window }}=50$ $H z$. For each time-window the mean has been subtracted from the FWH time-domain integrands, and no explicit filtering (i.e. a Box filter) was used in the present analysis. Next the Fast Fourier Transform (FFT) is applied to transform the integrands into the frequency domain. Once the FFT is complete, the FWH surface integrals are evaluated in the frequency domain at each observer location to construct the acoustic pressure 
$p^{\prime}$. The PSD is then averaged over the 33 windows and the resulting spectrum is compared to the wind tunnel results. ${ }^{1}$ Note the axis center for the far-field noise comparisons was set to 0.4 chord to be consistent with the JAXA wind tunnel measurements. This is different than the proplem statement specification of using the origin (i.e. the slat trailing edge) as the center.

Figure 21, Figure 22, and Figure 23 plot the predicted and experimental far-field spectrum at 10 chords from the $30 \mathrm{P} 30 \mathrm{~N}$ for three observer locations, $\theta=249,270$, and 291 degrees, at $\alpha=5.5,9.5$, and 14.0 degrees respectively. Note the wind-tunnel results are from the three shifted angles of attack $\alpha=7,11$, and 16 degrees. Good agreement is observed for all angles of attack at observer locations $\theta=270$ degrees and $\theta=291$ degrees for frequencies between 1-6 kHz. At observer location $\theta=249$ degrees the levels of the narrow-band peaks are good, but the broadband levels appear lower than the experiment. Below $1 \mathrm{kHz}$ there is a large difference in the far-field noise levels (upto $14 \mathrm{~dB}$ at $350 \mathrm{~Hz}$ ), in which the wind-tunnel data is measuring much larger PSD levels. This was surprising since the near-field PSD levels between the experiment and the simulation results were within 1-2 dB in this frequency range. The authors have assessed sensitivity to both windowing (using a Hanning window) and permeable surface compared to impermeable (using the unsteady airfoil surface data) with only 1-2 dB differences observed. One possibility for the difference is background tunnel noise which would not be accounted for in the current hybrid RANS-LES simulations. This will be investigated further in future work. Figure 24 plots the far-field PSD for all three angles of attack at each of the observer locations. The zonal hybrid RANS-LES method appears to capture the reduction of narrow band peaks with increasing angle of attack, as observed in the wind tunnel results, very well. It also shows a reduction in overall noise levels with increasing angle of attack, which was also observed in the wind-tunnel measurements.

Given the strong agreement between experiment and the hybrid RANS-LES simulations for frequencies between 1-6 kHz, the band-limited OASPL $([1-6] \mathrm{kHz})$ directivity is plotted in Figure 25 . The directivity plot shows the overall reduction in noise levels with increasing angle of the attack that was also oberved in the narrow-band spectrum at observer locations $\theta=249,270$, and 291 degrees. It also shows a shift in the low noise region from $\theta=360$ degrees at $\alpha=5.5$ to $\theta=350$ degrees at $\alpha=14.0$. This is associated with the effecting shielding of the slat cove by the main-element and the flap.

\section{Summary}

A efficient zonal hybrid RANS-LES method has been successfully applied to predict aeroacoustic slat noise from the 30P30N three-element high-lift system at high angles of attack. Spatially dependent spanwise grid spacings were utilized to reduce the number of grid points by more than half of what is typically used to achieve good results for this test case. The spatially varying span-wise mesh resolution was used in conjunction with spatially varying turbulence modeling closures, URANS (Mode 0) is used for most of the flow-field along with a relatively coarse span-wise grid spacing, DES (Mode 1) is used for the boundary layer region on the inner slat cove, and a new Mode 4 (LES) is introduced in this work, for specialized shear-layer grids not explicitly connected to wall boundaries. Both near-field and far-field PSD spectra are compared with experimental and previous workshop participant data. Good comparisons in near-field PSD levels are observed up to approximately $6 \mathrm{kHz}$, and between 1-6 $\mathrm{kHz}$ in the far-field. Three observations have been made regarding the effects of slat noise with increasing angle of attack. The first observation is a reduction in narrow band peaks with increasing angle of attack. The second effect is an overall reduction in broad-band noise levels with increasing angle of attack. The third effect is a minor shift in the low noise region of the directivity plot illustrating the shielding effect of the main-element and flap relative to the slat cove with respect to angle of attack. The first two observations were also observed in the wind tunnel data, and represented the main findings of that test. The good results observed using the efficient zonal hybrid RANS-LES method, which is designed to be economical enough to be applied to full-scale aircraft, suggests that the method is mature enough to explore slat noise on more complicated configurations.

\section{Acknowledgements}

This work is partially funded by the NASA Advanced Air Transport Technology (AATT) Aircraft Noise Reduction (ANR) project and NASA's Transformative, Tools, and Technology (TTT) project under NASA's ARMD Transformative Aeronautics Concepts Program (TACP). The authors would like to thank the $5^{\text {th }}$ AIAA Benchmark problems for Airframe Noise Computations Workshop committee members for organizing the workshop, specifically Meelan Choudhari of NASA Langley Research Center. Computer time was 
provided by NASA's Advanced Supercomputing (NAS) facility at NASA Ames Research Center.

\title{
References
}

\begin{abstract}
${ }^{1}$ Murayama, M., Yuzuru, Y., Ura, H., Kazuyuki, N., Kazuomi, Y., Ito, Y., Takaishi, T., Sakai, R., Shimoda, K., Kato, T., and Homma, T., "Experimental Study of Slat Noise from 30P30N Three-Element High-Lift Airfoil in JAXA Kevlar-Wall Low-Speed Wind Tunnel," 2018 AIAA/CEAS Aeroacoustics Conference, AIAA AVIATION Forum, 2018, AIAA-2018-3460.

${ }^{2}$ Terracol, M., Manoha, E., Murayama, M., Yamamoto, K., Amemiya, K., and Tanaka, K., "Aeracoustic Calculations of the 30P30N High-lift Airfoil using Hybrid RANS/LES methods: Modeling and Grid Resolution Effects," 2015 AIAA/CEAS Aeroacoustics Conference, AIAA AVIATION Forum, 2015, AIAA-2015-3132.

${ }^{3}$ Deck, S. and Larafaufie, R., "Numerical investigation of the flow dynamics past a three-element aerofoil," Journal of Fluid Mechanics, Vol. 732, 2013, pp. 401-444.

${ }^{4}$ Lockard, D. and Choudhari, M., "Noise Radiation from a Leading-Edge Slat," 15th AIAA/CEAS Aeroacoustics Conference, May 2009, AIAA-2009-3101.

${ }^{5}$ Choudhari, M. and Lockard, D. P., "Assessment of Slat Noise Predictions for 30P30N High-Lift Configuration from BANC-III workshop," 21st AIAA/CEAS Aeroacoustics Conference, Dallas, Texas, June 2015, AIAA-2015-3139.

${ }^{6}$ Paschal, K., Jenkins, L., and Yao, C., "Unsteady Slat-Wake Characteristics of a High-Lift Configuration," 38th Aerospace Sciences Meeting, Reno, Nevada, January 2000, AIAA-2000-0139.

${ }^{7}$ Jenkins, L., Khorrami, M., and Choudhari, M., "Characterization of Unsteady Flow Structures Near Leading-Edge Slat: Part I. PIV Measurements," 10th AIAA/CEAS Aeroacoustics Conference, Manchester, Great Britain, May 2004, AIAA-20042801.
\end{abstract}

${ }^{8}$ Murayama, M., Nakakita, K., Yamamoto, K., Ura, H., and Ito, Y., "Experimental Study of Slat Noise from 30P30N Three-Element High-Lift Airfoil in JAXA Hard-Wall Low-Speed Wind Tunnel," 20th AIAA/CEAS Aeroacoustics Conference, June 2014, AIAA-2014-2080.

${ }^{9}$ Pascioni, K. A., Cattafesta, L. N., and Choudhari, M. M., "An Experimental Investigation of the 30P30N Multi-Element High-Lift Airfoil," 20th AIAA/CEAS Aeroacoustics Conference, June 2014, AIAA-2014-3062.

${ }^{10}$ Khorrami, M., Choudhari, M., and Jenkins, L., "Characterization of Unsteady Flow Structures Near Leading-Edge Slat: Part II. 2D Computations," 10th AIAA/CEAS Aeroacoustics Conference, Manchester, Great Britain, May 2004, AIAA-20042802.

${ }^{11}$ Choudhari, M. and Khorrami, M., "Effect of Three-Dimensional Shear-Layer Structures on Slat Cove Unsteadiness," AIAA Journal, Vol. 45, No. 9, 2007, pp. 2174-2186.

${ }^{12}$ Lockard, D. and. Choudhari, M. and Buning, P., "Grid Sensitivity Study for Slat Noise Simulations," 2014 AIAA/CEAS Aeroacoustics Conference, AIAA AVIATION Forum, 2014, AIAA-2014-2627.

${ }^{13}$ Ashton, N., West, A., and Mendonca, F., "Slat Noise Prediction using Hybrid RANS-LES methods on Structured and Unstructured Grids," 21st AIAA/CEAS Aeroacoustics Conference, Dallas, Texas, June 2015, AIAA-2015-3139.

${ }^{14}$ Kiris, C., Housman, J., Barad, M., Brehm, C., Sozer, E., and Moini-Yekta, S., "Computational Framework for Launch, Ascent, and Vehicle Aerodynamics (LAVA)," Aerospace Science and Technology, Vol. 55, August 2016, pp. 189-219.

${ }^{15}$ Bahr, C., Hutcheson, F., Thomas, R., and Housman, J., "A Comparison of the Noise Characteristics of a Conventional Slat and Krueger Flap," 22nd AIAA/CEAS Aeroacoustics Conference, Lyon, France, May 2016, AIAA-2016-2961.

${ }^{16}$ Housman, J. and Kiris, C., "Slat Noise Predictions using Higher-Order Finite-Difference Methods on Overset Grids," 22nd AIAA/CEAS Aeroacoustic Conference, Lyon, France, May 30-31 2016, AIAA-2016-2963.

${ }^{17}$ Chan, W., "Developments in Strategies and Software Tools for Overset Structured Grid Generation and Connectivity," 20th AIAA Computational Fluid Dynamics Conference, Honolulu, Hawaii, June 2011, AIAA-2011-3051.

${ }^{18}$ Steger, J. L. and Benek, J. A., "On the Use of Composite Grid Schemes in Computational Aerodynamics," Technical Memorandum 88372, NASA, 1986.

${ }^{19}$ Chan, W., Gomez, R. J., Rogers, S., and Buning, P., "Best Practices in Overset Grid Generation," 32nd AIAA Fluid Dynamics Conference and Exhibit, St. Louis, Missouri, June 24-26, 2002, AIAA-2002-3191.

${ }^{20}$ Rogers, S. E., Roth, K. R., M., N. S., Baker, M. D., Slotnick, J. P., Whitlock, M., and Cao, H. V., "Advances in Overset CFD Processes Applied to Subsonic High-Lift Aircraft," 18th AIAA Applied Aerodynamics Conference, Denver, CO, 2000, AIAA-2000-4216.

${ }^{21}$ Vinokur, M., "Conservation Equations of Gasdynamics in Curvilinear Coordinate Systems," Journal of Computational Physics, Vol. 14, 1974, pp. 105-125.

${ }^{22}$ Spalart, S. R. and Allmaras, S. A., "A One-Equation Turbulence Model for Aerodynamic Flows," 30th Aerospace Sciences Meeting and Exhibit, Reno, NV, January 1992, AIAA-92-0439.

${ }^{23}$ Deck, S., "Recent improvements in the zonal detached-eddy simulation (ZDES) formulation," Theoretical and Computational Fluid Dynamics, Vol. 26, 2012, pp. 523-550.

${ }^{24}$ Spalart, S. R., Jou, W.-H., Strelets, M., and Allmaras, S. R., "Comments on the feasibility of LES for wings, and on a hybrid RANS/LES approach," First AFOSR international conference on DNS/LES, Ruston, Louisiana, August 1997, Greyden Press.

${ }^{25}$ Strelets, M., "Detached eddy simulation of massively separated flows," 39th Aerospace Sciences Meeting and Exhibit, Reno, Nevada, January 2001, AIAA-2001-0879.

${ }^{26}$ Spalart, P. R., Deck, S., Shur, M. L., Squires, K. D., M., S., and Travin, A., "A new version of detached-eddy simulation, resistant to ambiguous grid densities," Theoretical and Computational Fluid Dynamics, Vol. 20, 2006, pp. 181-195.

${ }^{27}$ Shur, M., Spalart, P. R., Strelets, M., and Travin, A., "A hybrid RANS-LES approach with delayed-DES and wallmodelled LES capabilities," International Journal of Heat and Fluid Flow, Vol. 29, 2008, pp. 1638-1649.

${ }^{28}$ Spalart, P. R., "Detached-Eddy Simulation," Annual Review Fluid Mechanics, Vol. 41, 2009, pp. 181-202. 
${ }^{29}$ Caruelle, B. and Ducros, F., "Detached-Eddy Simulations of Attached and Detached Boundary Layers," International Journal of Computational Fluid Dynamics, Vol. 17, 2003, pp. 433-451.

${ }^{30}$ Eastwood, S., Xia, H., and Tucker, P., "Large-Eddy Simulation of Complex Geometry Jets," Journal of Propulsion and Power, Vol. 28, No. 2, March-April 2012, pp. 235-245.

${ }^{31}$ Zhu, H., Fu, S., Shi, L., and Wang, Z., "A Hybrid RANS-Implicit LES Approach for the High-Order FR/CPR Method," 54th AIAA Aerospace Sciences Meeting, San Diego, Ca., January 2016, AIAA-2016-1599.

${ }^{32}$ Chauvet, N., Deck, S., and Jacquin, L., "Zonal detached eddy simulation of a controlled propulsive jet," AIAA Journal, Vol. 45, No. 10, 2007, pp. 2458-2473.

${ }^{33}$ Deck, S., Weiss, P., Pamies, M., and Garnier, E., "Zonal Detached Eddy Simulation of spatially developing flat plate turbulent boundary layer," Computers and Fluids, Vol. 48, 2011, pp. 1-15.

${ }^{34}$ Deck, S., Renard, N., Laraufie, R., and Sagaut, P., "Zonal detached eddy Simulation (ZDES) of a spatially developing flat plate turbulent boundary layer over the Reynolds number range $3150 \leq R e_{\theta} \leq 14000$," Physics of Fluids, Vol. $26,2014$.

${ }^{35}$ Renard, N. and Deck, S., "Improvements in Zonal Detached Eddy Simulation for Wall Modeled Large Eddy Simulation," Physics of Fluids, Vol. 26, 2014.

${ }^{36}$ Stich, G., Housman, J., Kocheemoolayil, J., Barad, M., and Kiris, C., "Application of Lattice Boltzmann and NavierStokes Methods to NASA's Wall Mounted Hump," 2018 Fluid Dynamics Conference, AIAA AVIATION Forum, 2018, AIAA2018-3855.

${ }^{37}$ Brehm, C., Housman, J., Kiris, C., and Hutcheson, F., "Noise Characteristics of a Four-Jet Impingement Device Inside a Broadband Engine Noise Simulator," 21st AIAA/CEAS Aeroacoustics Conference, Dallas, Texas, June 2015, AIAA-2015-2211.

${ }^{38}$ Housman, J. and Kiris, C., "Structured Overlapping Grid Simulations of Contra-Rotating Open Rotor Noise," 54 th AIAA Aerospace Sciences Meeting, January 4-8 2016, AIAA-2016-0814.

${ }^{39}$ Brehm, C., Housman, J., and Kiris, C., "Noise Generation Mechanisms for a supersonic jet impinging on an inclined plate," Journal of Fluid Mechanics, Vol. 797, 2016, pp. 802-850.

${ }^{40}$ Brehm, C., Housman, J., and Kiris, C., "Noise Generation Mechanisms for a Supersonic Jet Impinging on an Inclined Plate," Journal of Fluid Mechanics, 2015, In review.

${ }^{41}$ Shu, C.-W., "High Order Weighted Essentially Nonoscillatory Schemes for Convection Dominated Problems," SIAM Review, Vol. 51, No. 1, 2009, pp. 92-126.

${ }^{42}$ Deng, X. and H., Z., "Developing High-Order Weighted Compact Nonlinear Schemes," Journal of Computational Physics, Vol. 165, 2000, pp. 22-44.

${ }^{43}$ Vinokur, M. and Yee, H., "Extension of Efficient Low Dissipation High Order Schemes for 3-D Curvilinear Moving Grids," Frontiers of Computational Fluid Dynamics, World Scientific, 2002, pp. 129-163, edited by D. A. Caughey and M. M. Hafez.

${ }^{44}$ Deng, X., Mao, M., Tu, G., Liu, H., and Zhang, H., "Geometric conservation law and applications to high-order finite difference schemes with stationary grids," Journal of Computational Physics, Vol. 230, 2011, pp. 1100-1115.

${ }^{45}$ Housman, J., Kiris, C., and Hafez, M., "Preconditioned methods for simulations of low speed compressible flows," Computes and Fluids, Vol. 38, No. 7, August 2009, pp. 1411-1423.

${ }^{46}$ Housman, J., Kiris, C., and Hafez, M., "Time-Derivative Preconditioning Methods for Multicomponent Flows - Part I: Riemann Problems," Journal of Applied Mechanics, Vol. 76, No. 2, February 2009.

${ }^{47}$ Housman, J., Kiris, C., and Hafez, M., "Time-Derivative Preconditioning Methods for Multicomponent Flows - Part II: Two-Dimensional Applications," Journal of Applied Mechanics, Vol. 76, No. 3, March 2009.

${ }^{48}$ Deng, X., Mao, M., Jiang, Y., and Liu, H., "New High-Order Hybrid Cell-Edge and Cell-Node Weighted Compact Nonlinear Schemes," 20th AIAA Computational Fluid Dynamics Conference, Honolulu, Hawaii, June 2011, AIAA-2011-3857.

${ }^{49}$ Nonomura, T. and Fujii, K., "Robust explicit formulation of weighted compact nonlinear scheme," Computers Eु Fluids, Vol. 85, 2013, pp. 8-18.

${ }^{50}$ Lockard, D. P., "A Comparison of Ffowcs Williams-Hawkings Solvers for Airframe Noise Applications," 8th AIAA/CEAS Aeroacoustics Conference, Breckenridge, Colorado, June 2002, AIAA-2002-2580.

${ }^{51}$ Bres, G., Nichols, J., Lele, S., and Ham, F., "Towards Best Practices for Jet Noise Predictions with Unstructured Large Eddy Simulations," 42nd AIAA Fluid Dynamics Conference, New Orleans, Louisiana, June 2012, AIAA-2012-2965.

${ }^{52}$ Bres, G., Nichols, J., Lele, S., and Ham, F., "Large Eddy Simulation for Jet Noise: the Importance of Getting the Boundary Layer Right," 21st AIAA/CEAS Aeroacoustics Conference, Dallas, Texas, June 2015, AIAA-2015-2535.

${ }^{53}$ Spalart, P. R. and Shur, M., "Variants of the Ffowcs Williams-Hawkings Equation and their Coupling with Simulations of Hot Jets," International Journal of Aeroacoutics, Vol. 8, No. 5, 2009, pp. 477-492. 


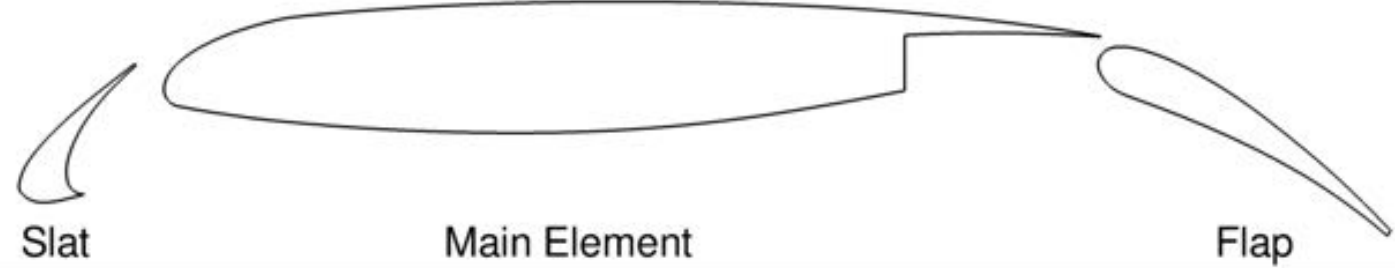

Figure 1. Cross-section of the 30P30N 3-element high-lift configuration.

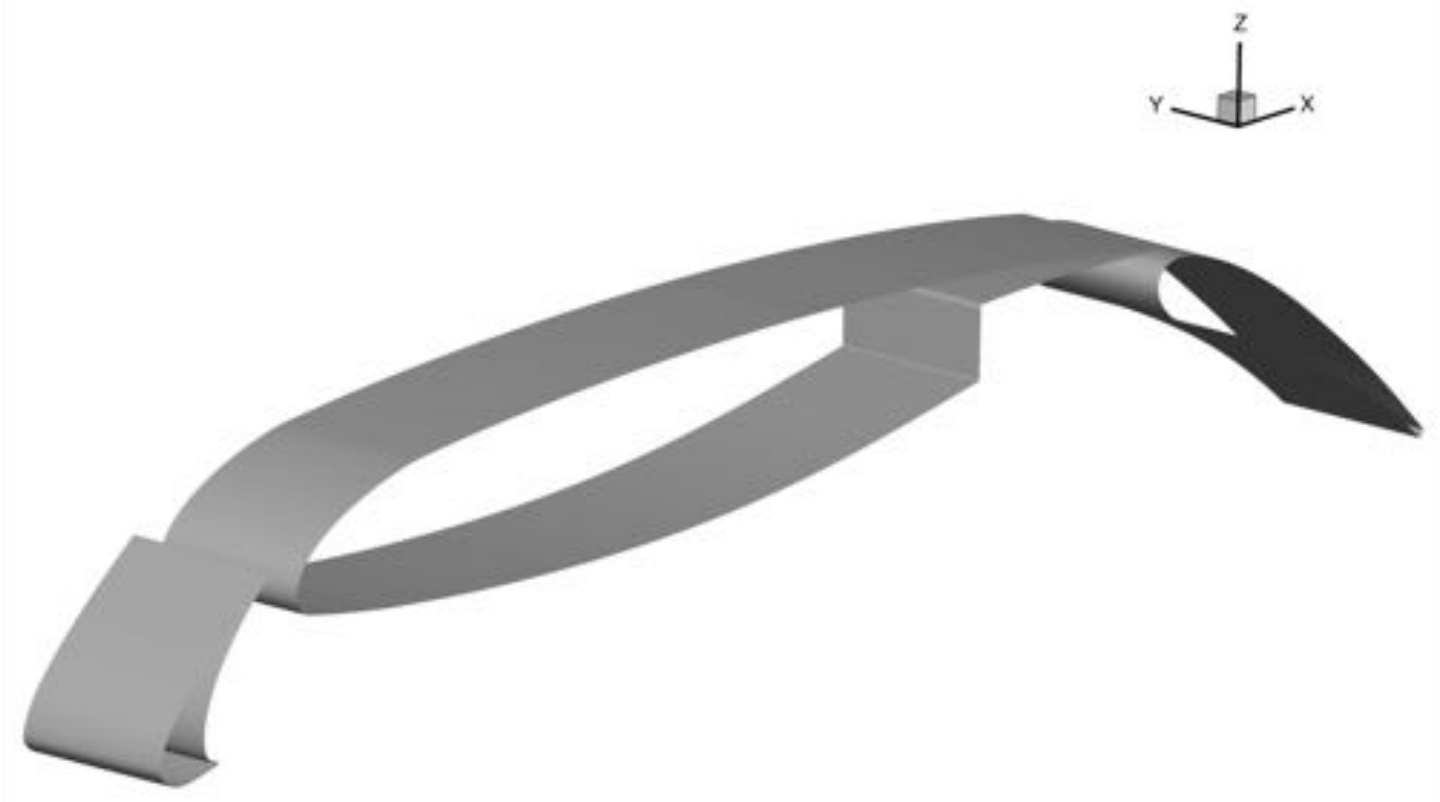

Figure 2. Iso-parametric view of the $30 \mathrm{P} 30 \mathrm{~N}$ illustrating the finite-span used in the simulations. 


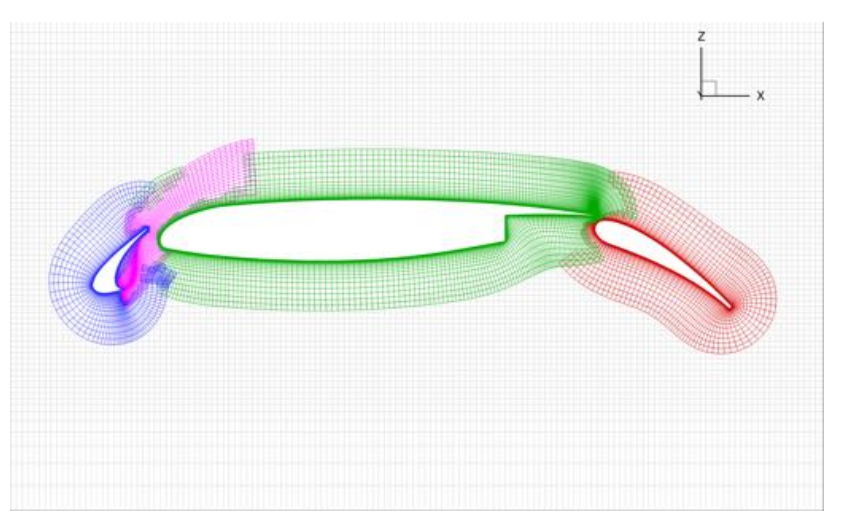

(a) Coarse: $68 \mathrm{~K}$ grid points

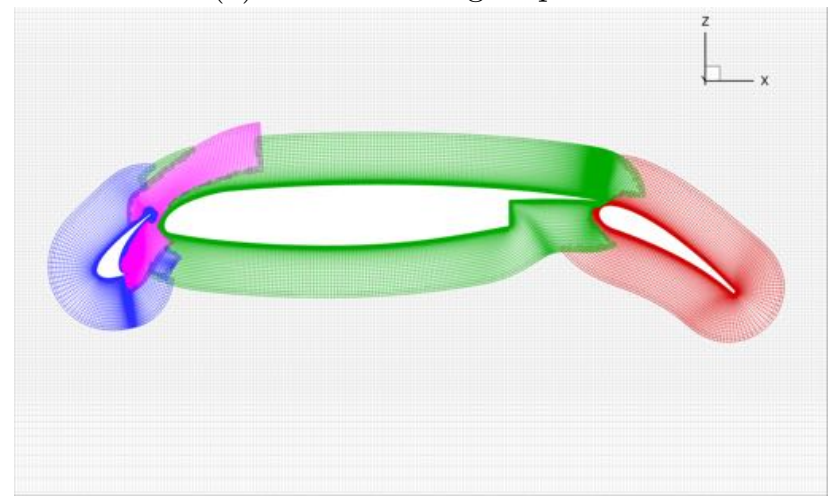

(c) Fine: $259 \mathrm{~K}$ grid points

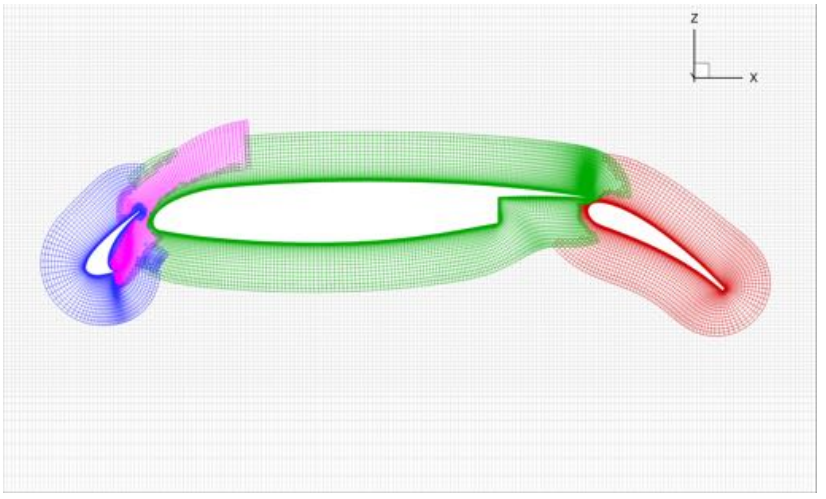

(b) Medium:128K grid points

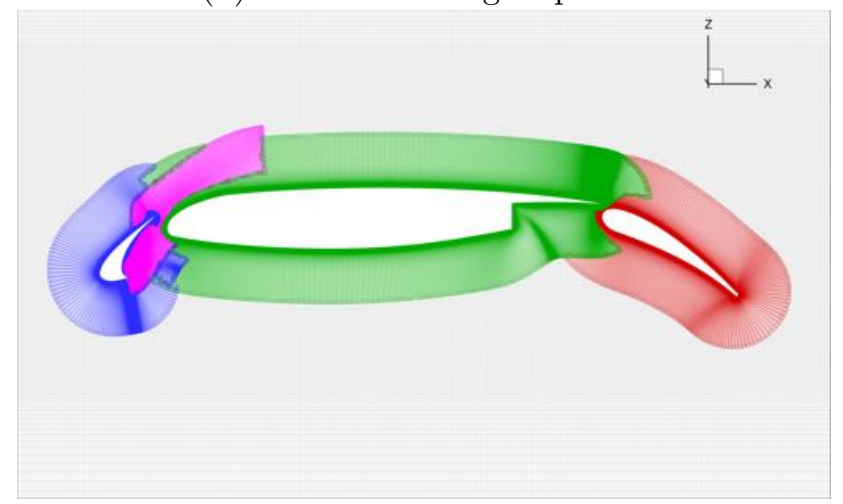

(d) Extra Fine: $435 \mathrm{~K}$ grid points

Figure 3. Family of two-dimensional, single plane, structured overset grid systems for the 30P30N high-lift system.

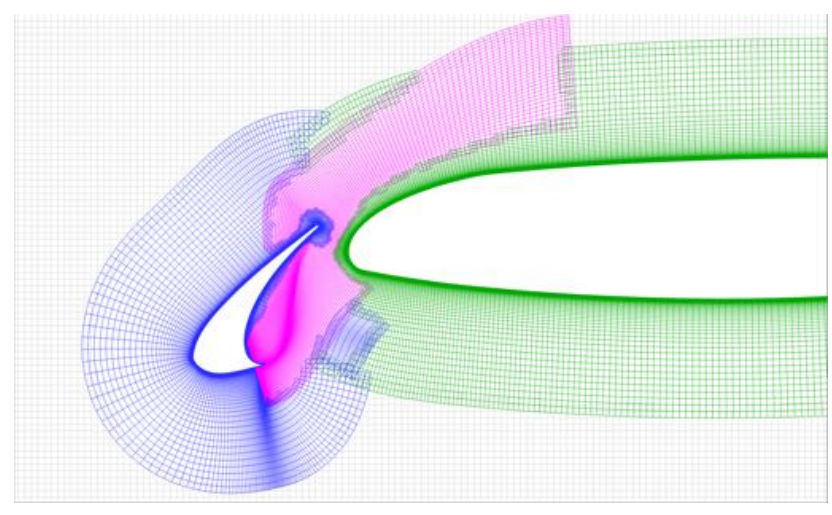

(a)

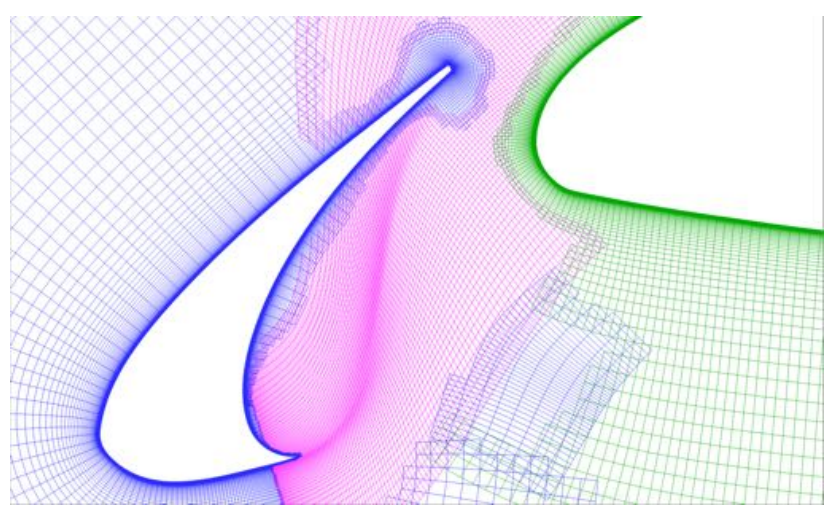

(b)

Figure 4. Close-up views of the slat cove mesh for the fine grid. 


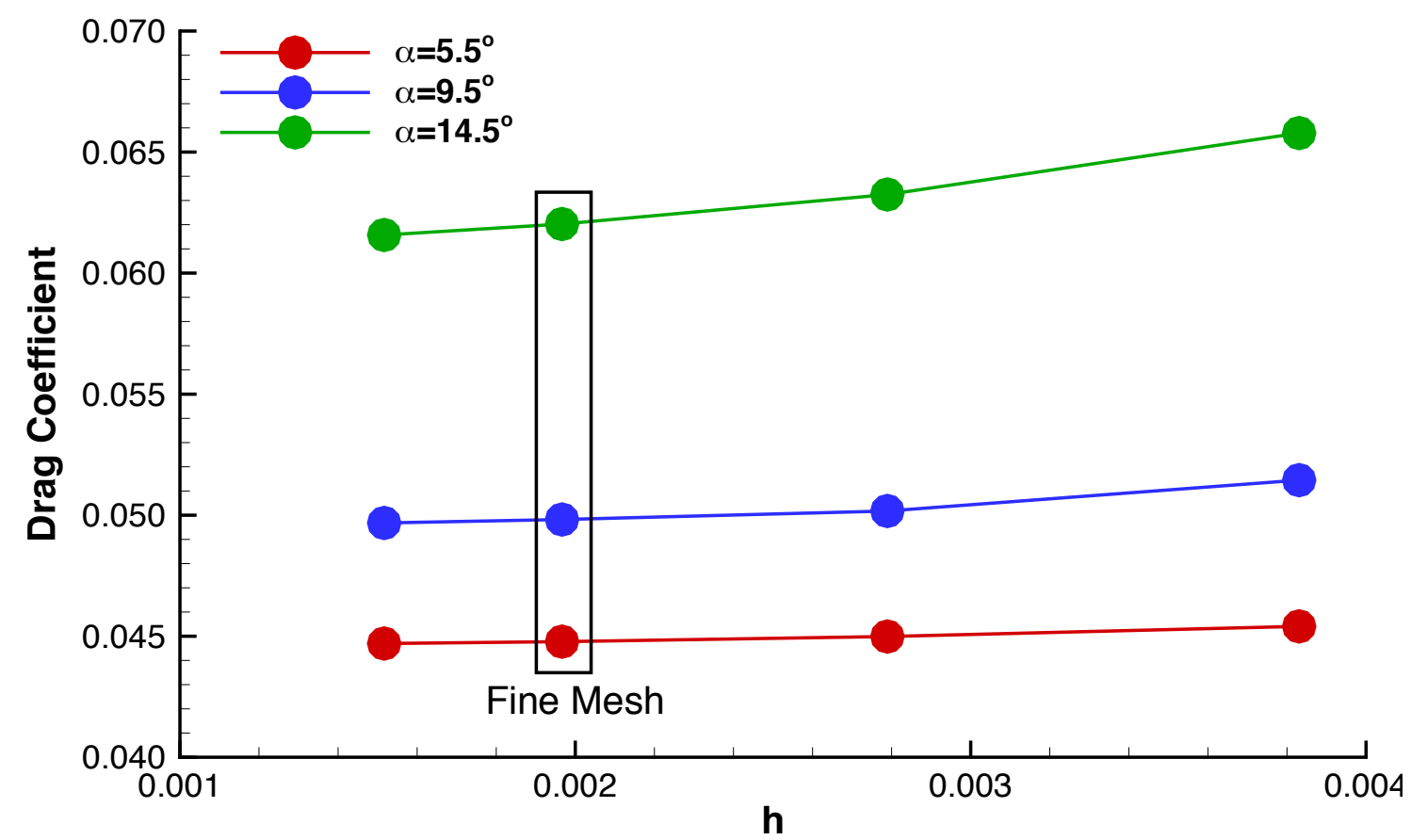

Figure 5. Mesh convergence of drag coefficient for 2D steady-state RANS analysis on the family of structured overset grids.

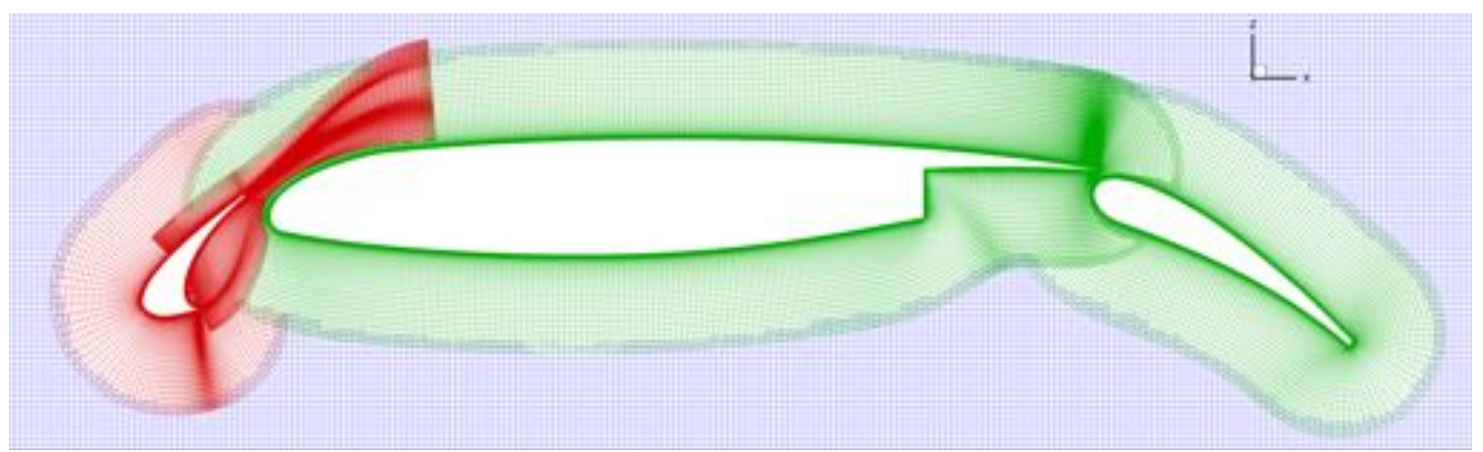

Figure 6. Structured overset grid system in which each color represents a different span-wise grid resolution: (red) $N_{\text {span }}=256$, (green) $N_{\text {span }}=128$, and (blue) $N_{\text {span }}=64$.

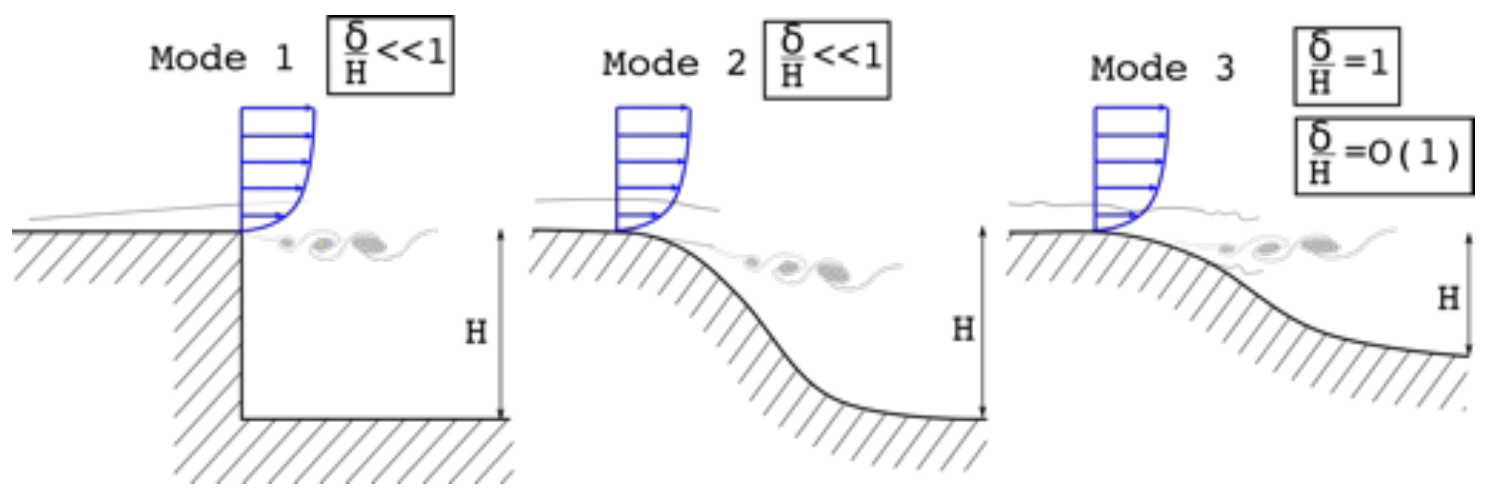

Figure 7. Classification of canonical flow problems by mode following Deck et.al.: (1) separation fixed by geometry, (2) separation induced by pressure gradient on curved surface, (3) separation strongly dependent on dynamics of incoming boundary layer. 


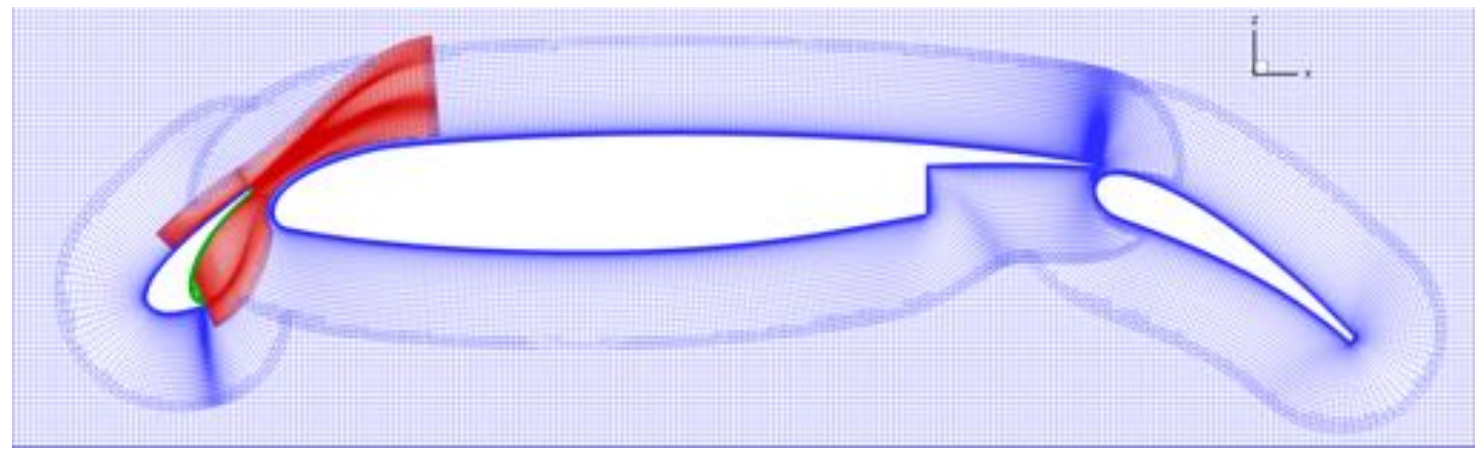

(a) Global view

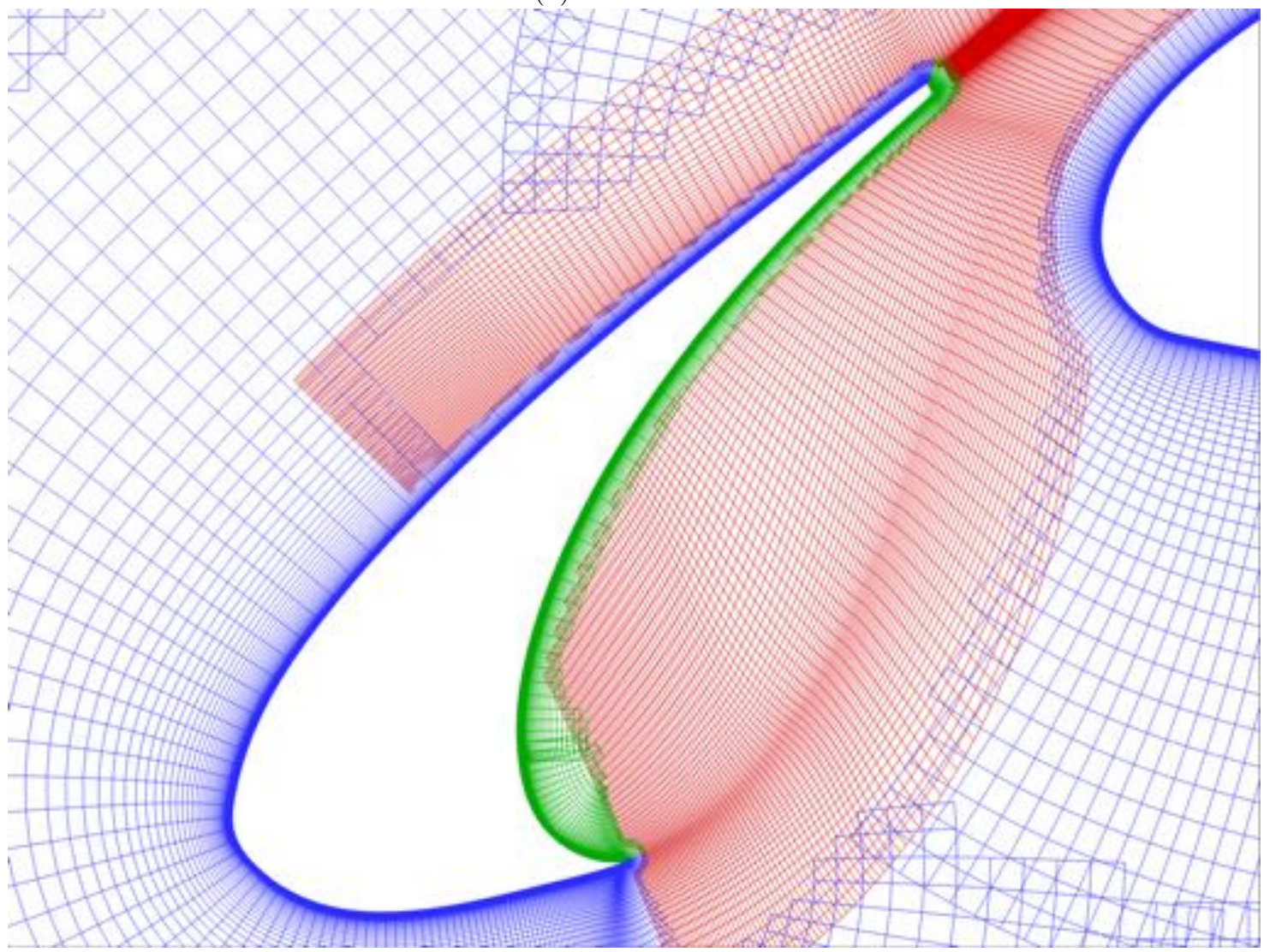

(b) Close-up of slat cove region

Figure 8. Structured overset grid system colored by ZDES Mode selection: (blue) ZDES-Mode 0 standard SA-RANS, (green) ZDES-Mode 1 SA-DES97, (red) ZDES-Mode 4 LES. (a) Shows a global view of the grid system and (b) shows a close-up of the slat cove region. 

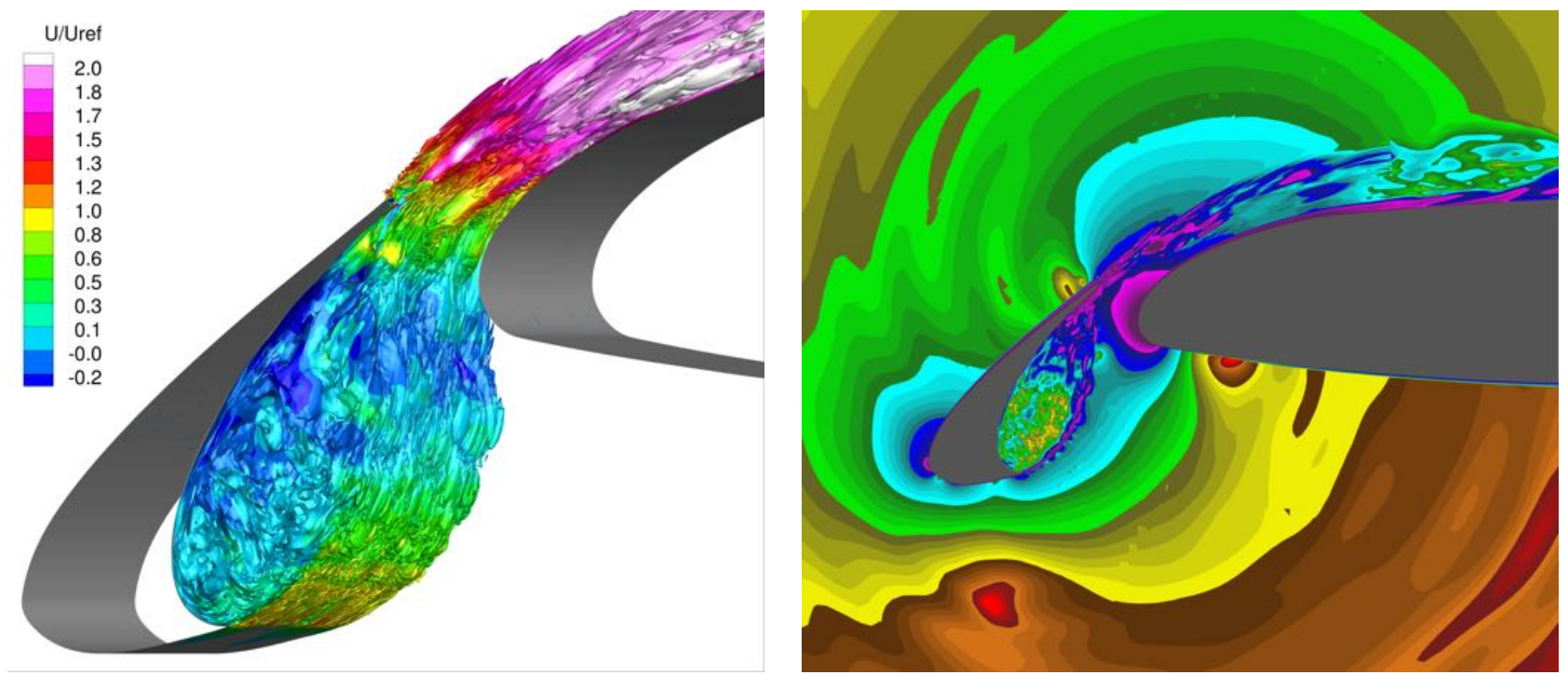

(a) $\alpha=5.5$ degrees
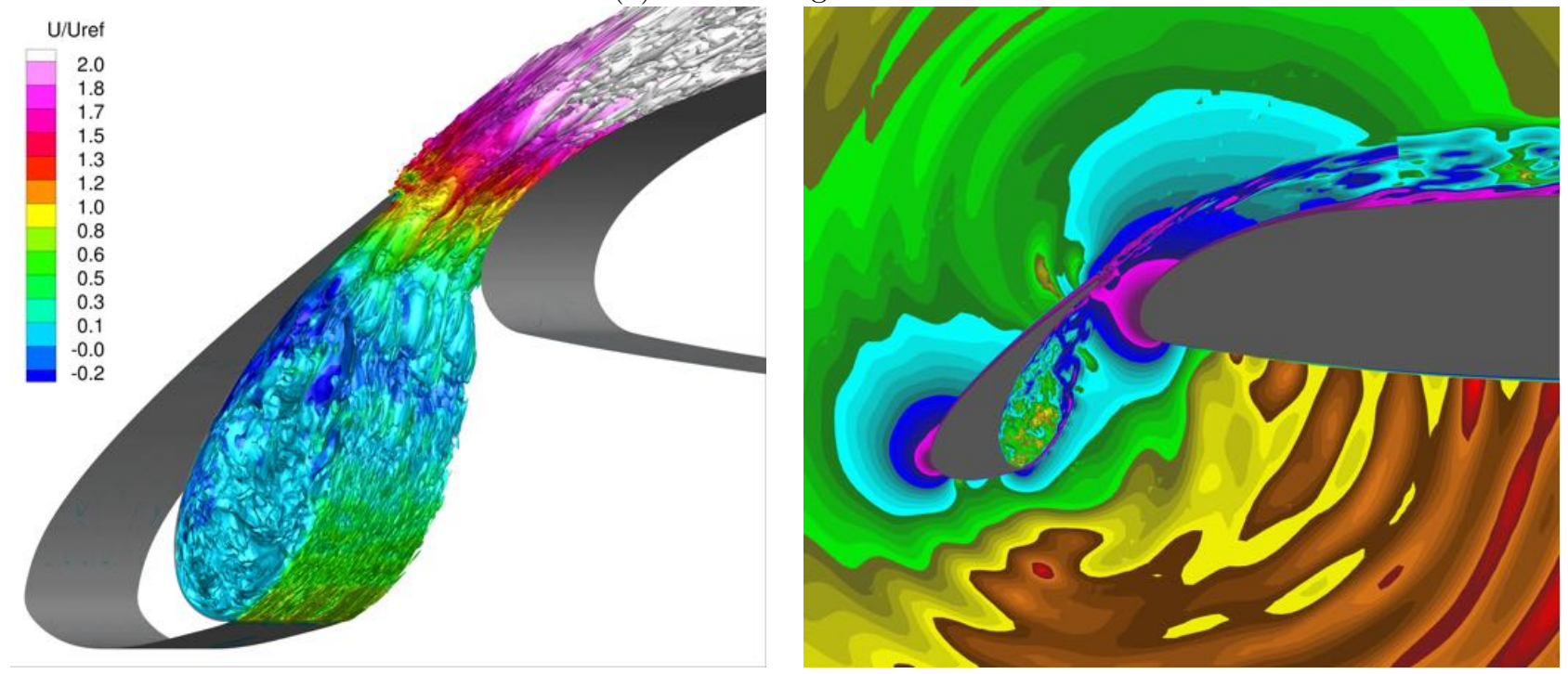

(b) $\alpha=9.5$ degrees
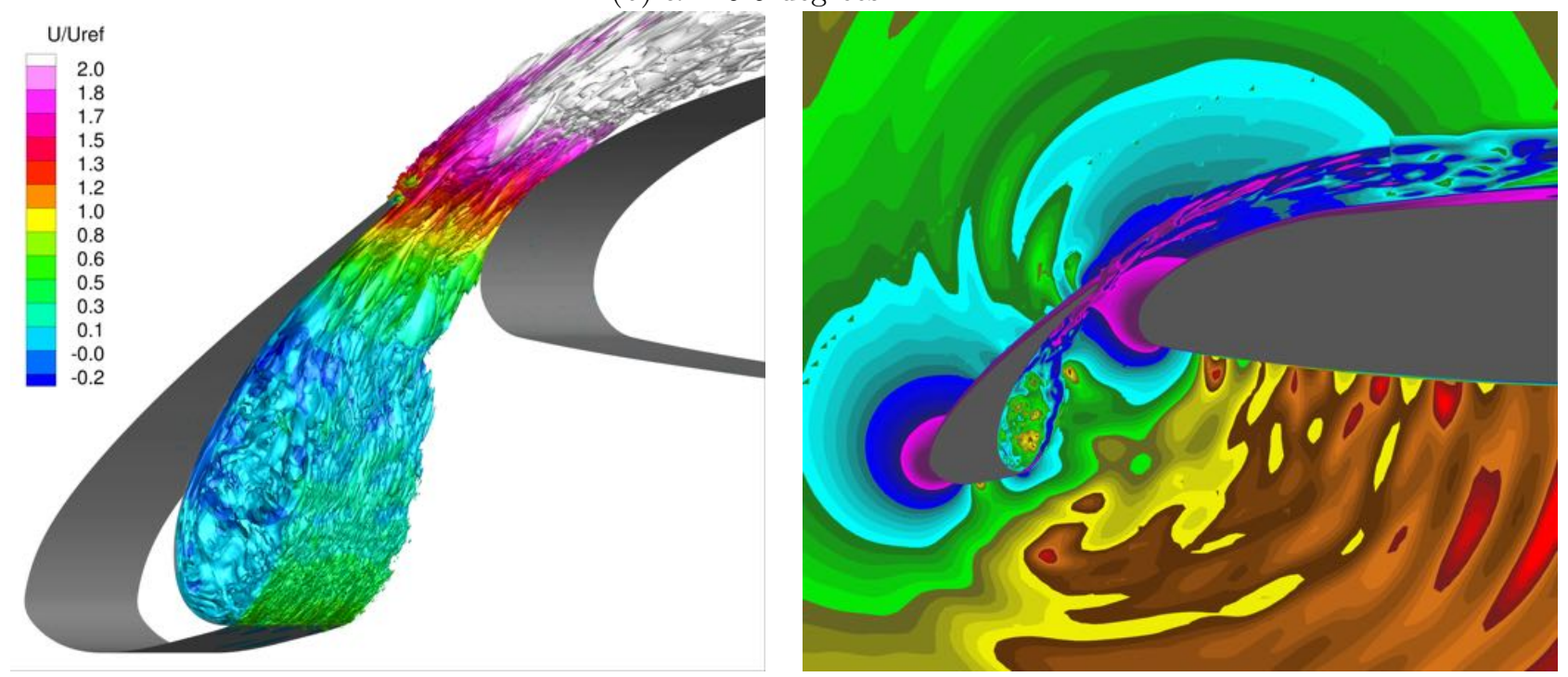

(c) $\alpha=14.0$ degrees

Figure 9. Instantaneous iso-contour of $x$-vorticity colored by normalized velocity (left) and contour plot of density gradient magnitude (right) at each angle of attack (a) $\alpha=5.5$, (b) $\alpha=9.5$, and (c) $\alpha=14.0$ degrees. 

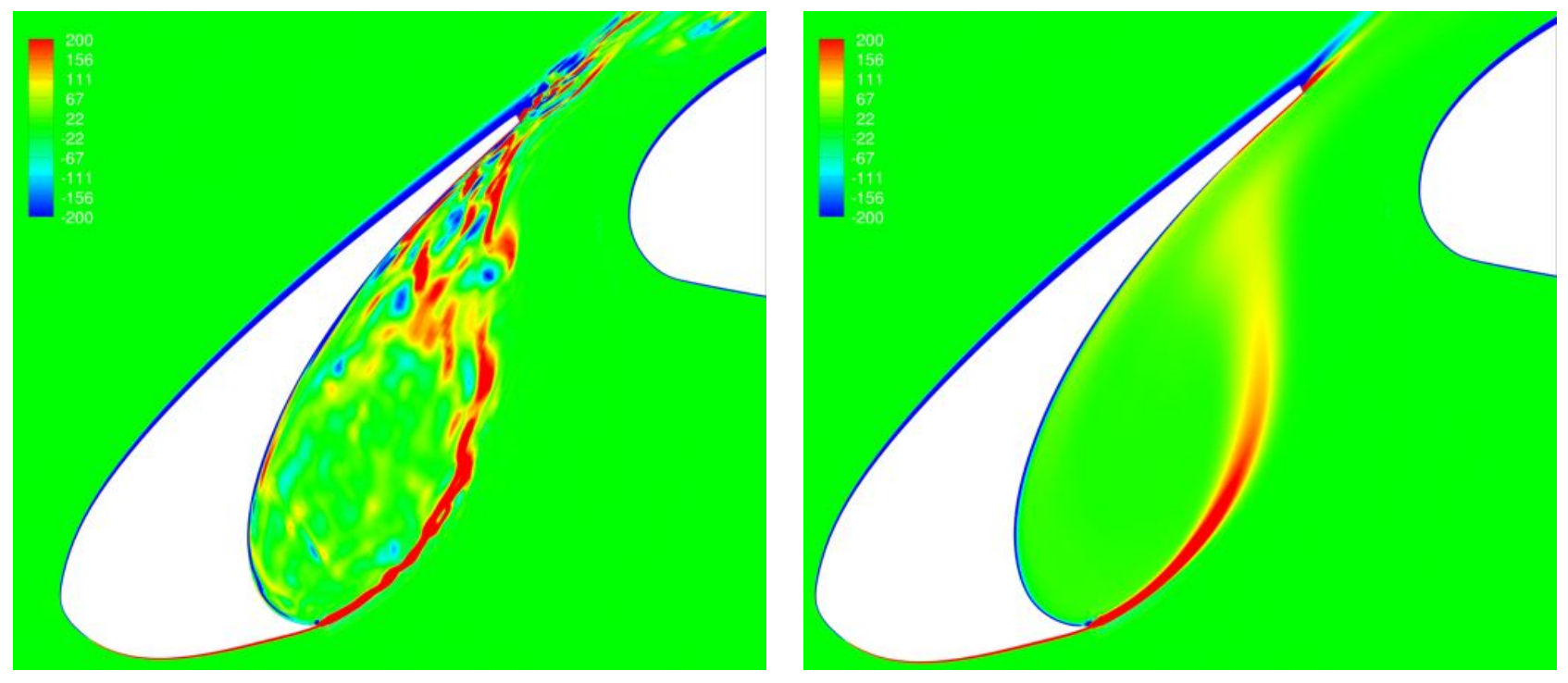

(a) $\alpha=5.5$ degrees
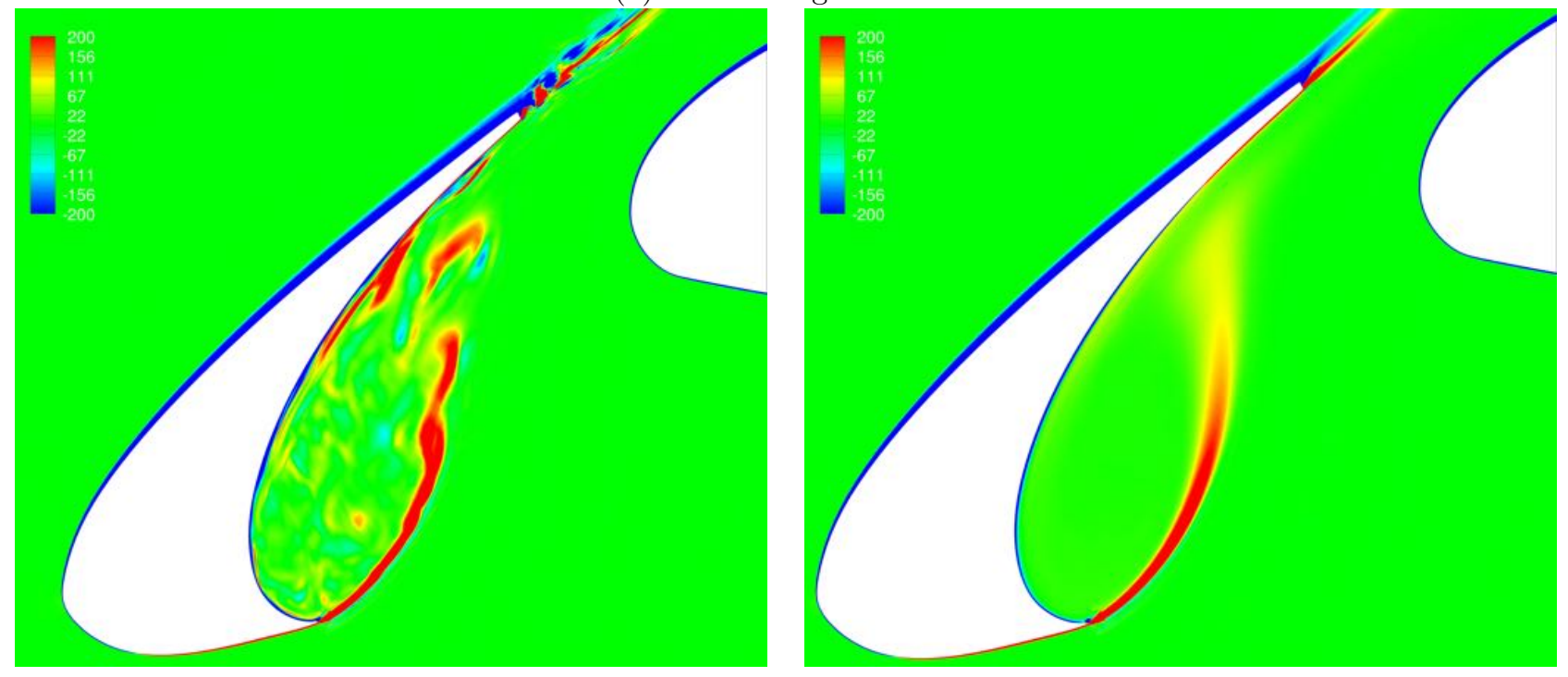

(b) $\alpha=9.5$ degrees
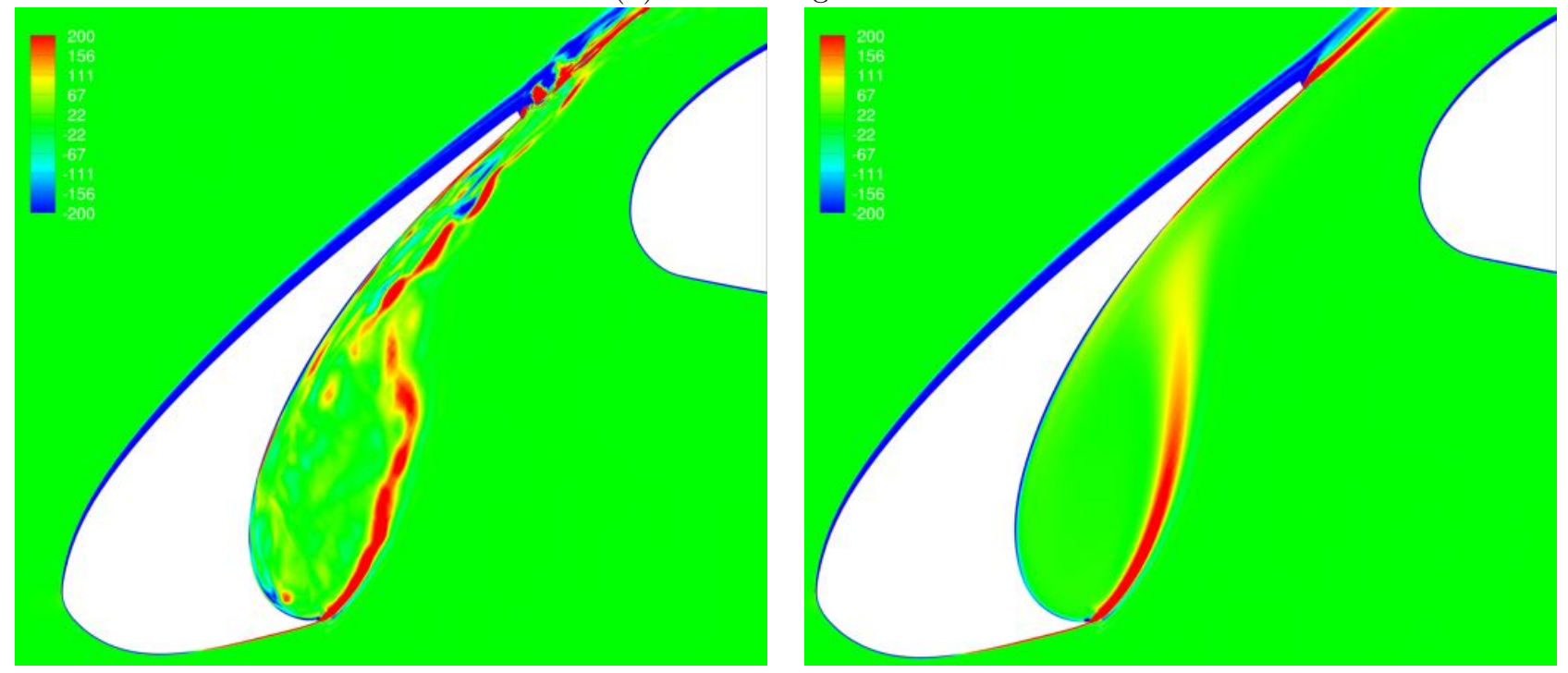

(c) $\alpha=14.0$ degrees

Figure 10. Contour plots of instantaneous span-wise vorticity (left) and time-averaged span-wise vorticity (right) at each angle of attack (a) $\alpha=5.5$, (b) $\alpha=9.5$, and (c) $\alpha=14.0$ degrees.

\section{6 of 27}



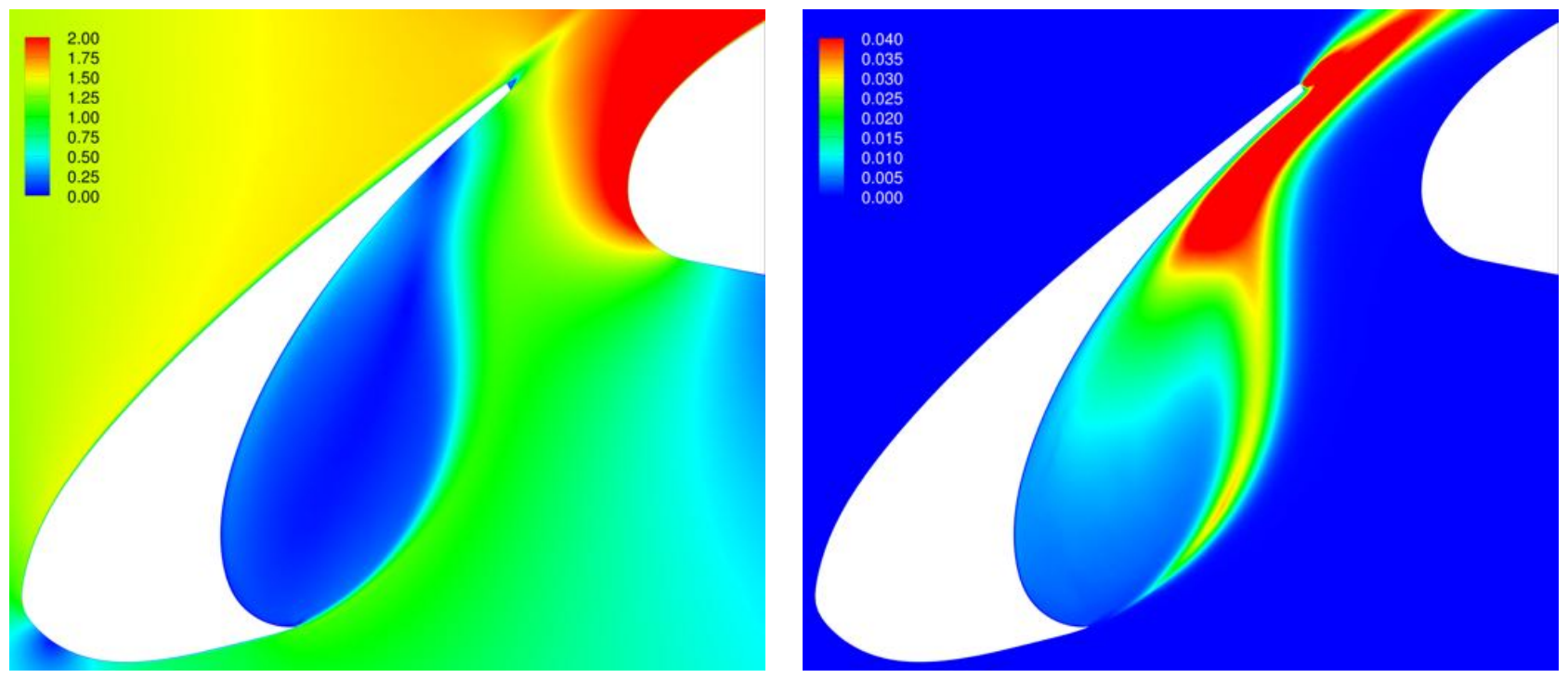

(a) $\alpha=5.5$ degrees
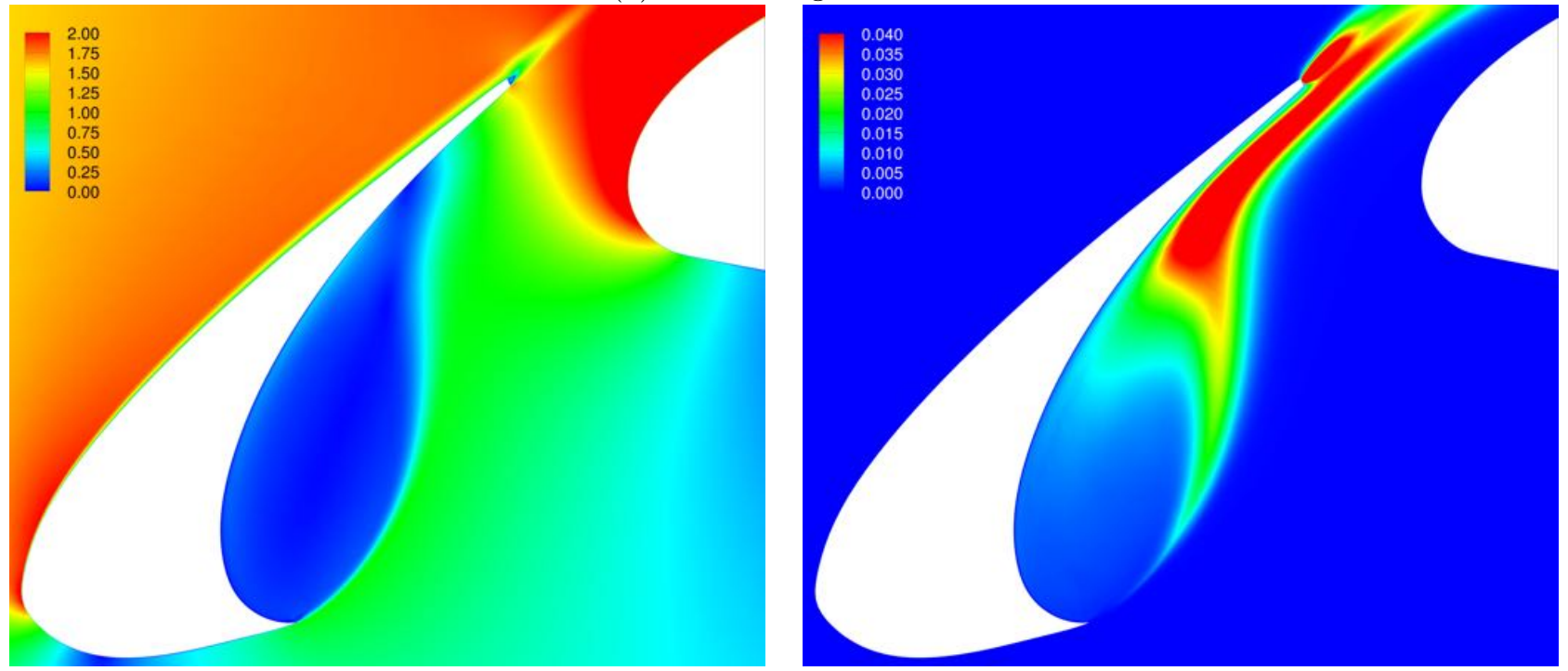

(b) $\alpha=9.5$ degrees
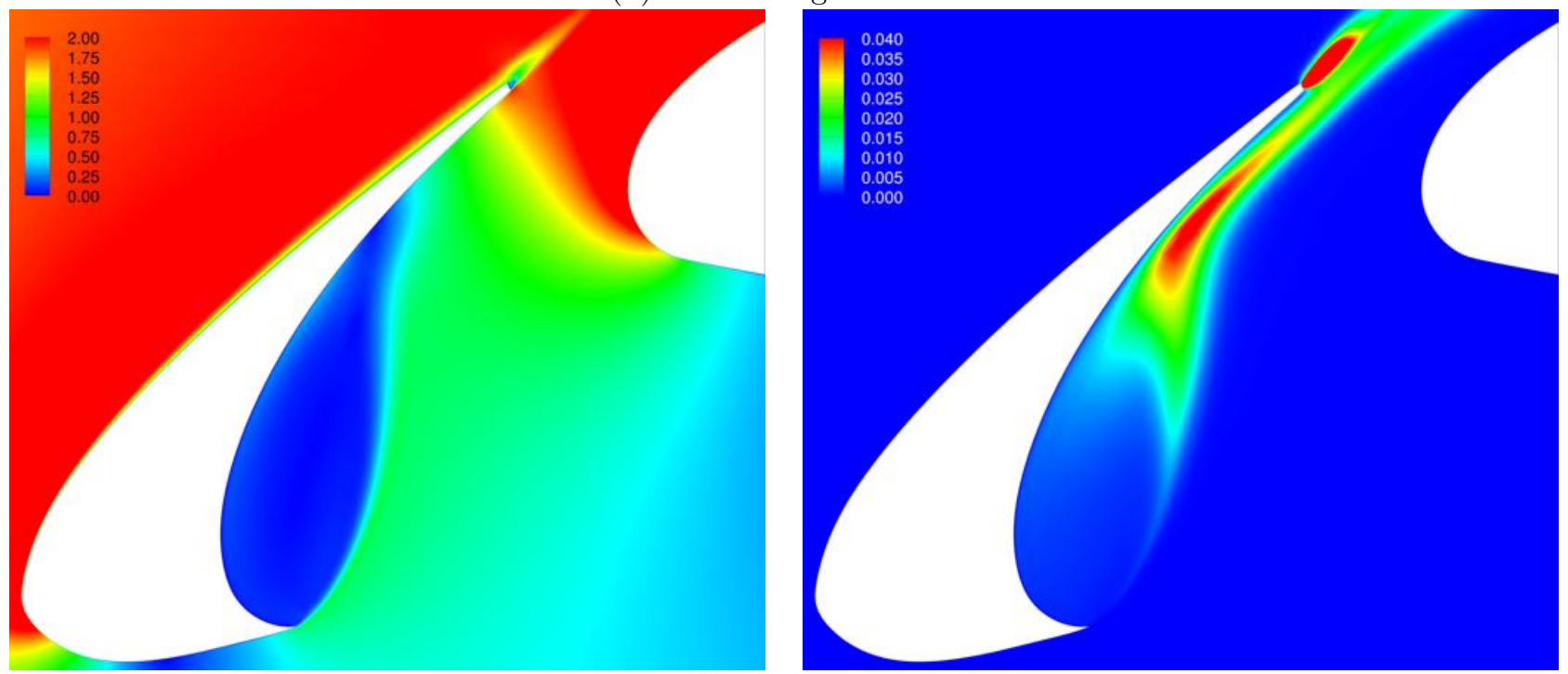

(c) $\alpha=14.0$ degrees

Figure 11. Contour plots of time-averaged two-dimensional velocity magnitude (left) and two-dimensional turbulent kinetic energy (right) at each angle of attack (a) $\alpha=5.5$, (b) $\alpha=9.5$, and (c) $\alpha=14.0$ degrees.

\section{7 of 27}




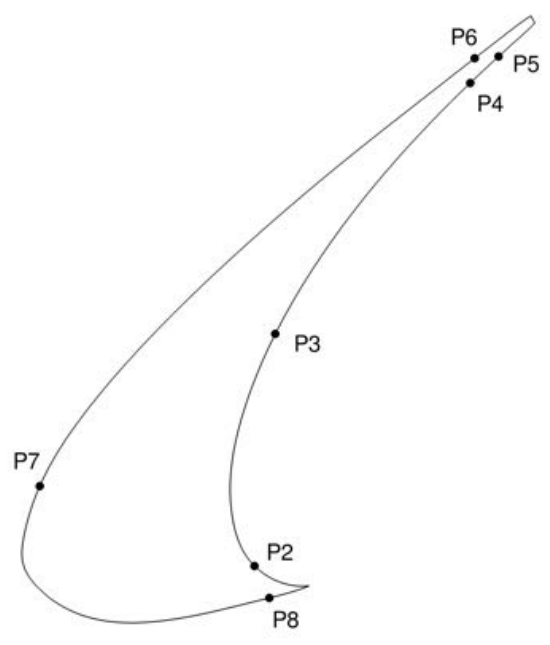

(a) PSD sensor locations

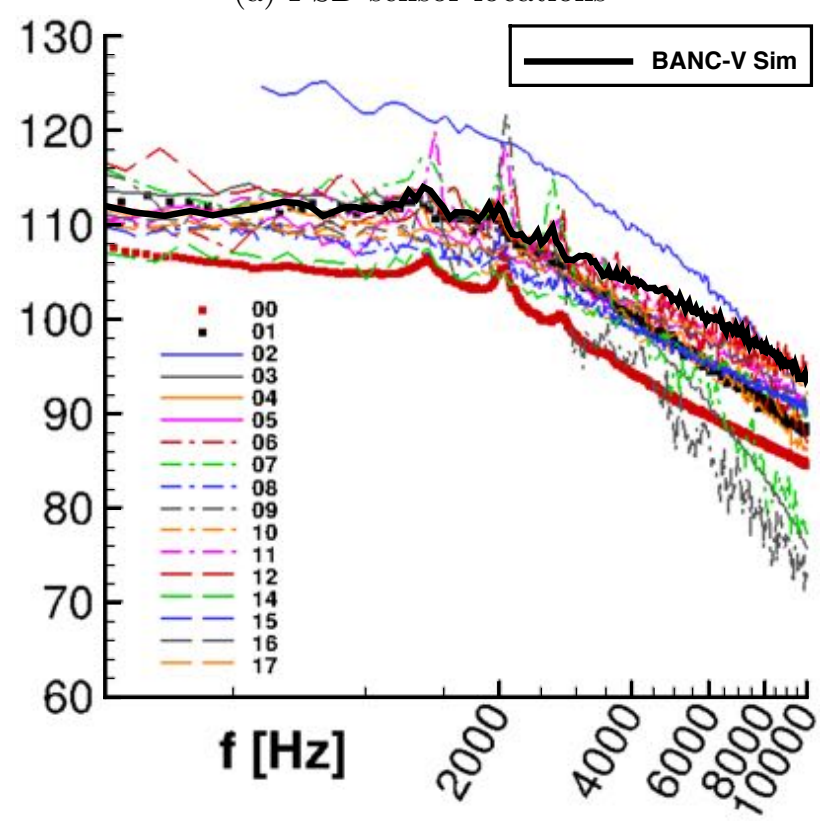

(c) Point sensor 4

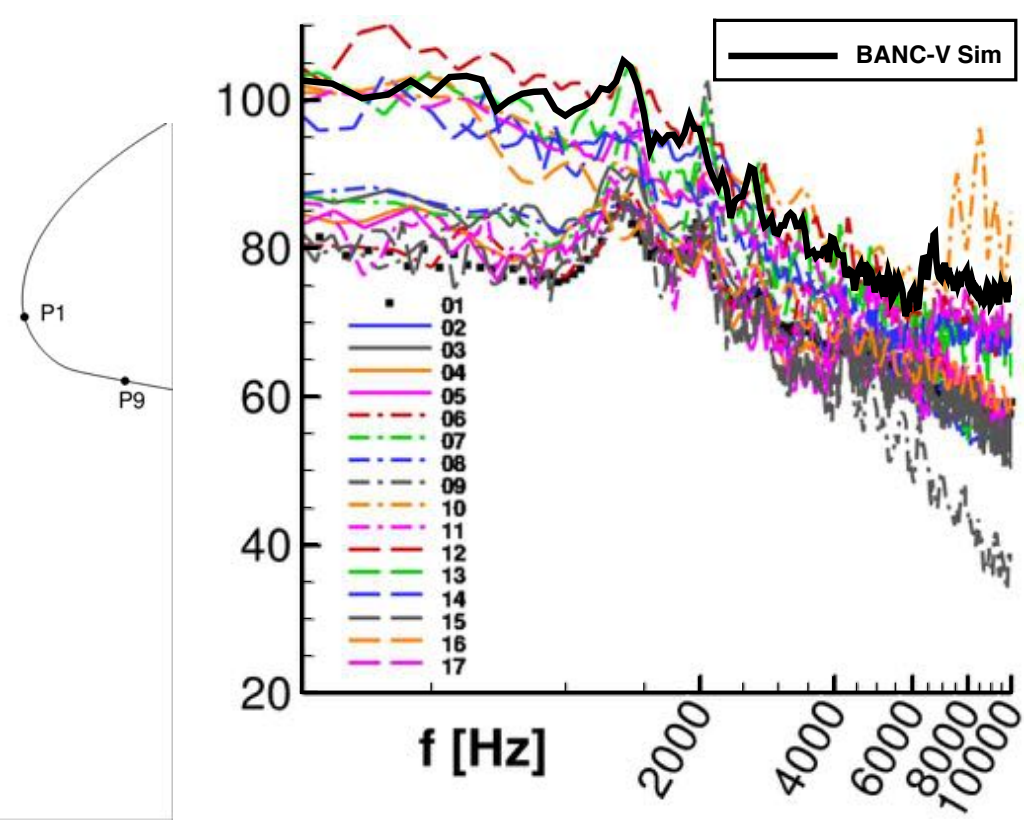

(b) Point sensor 1

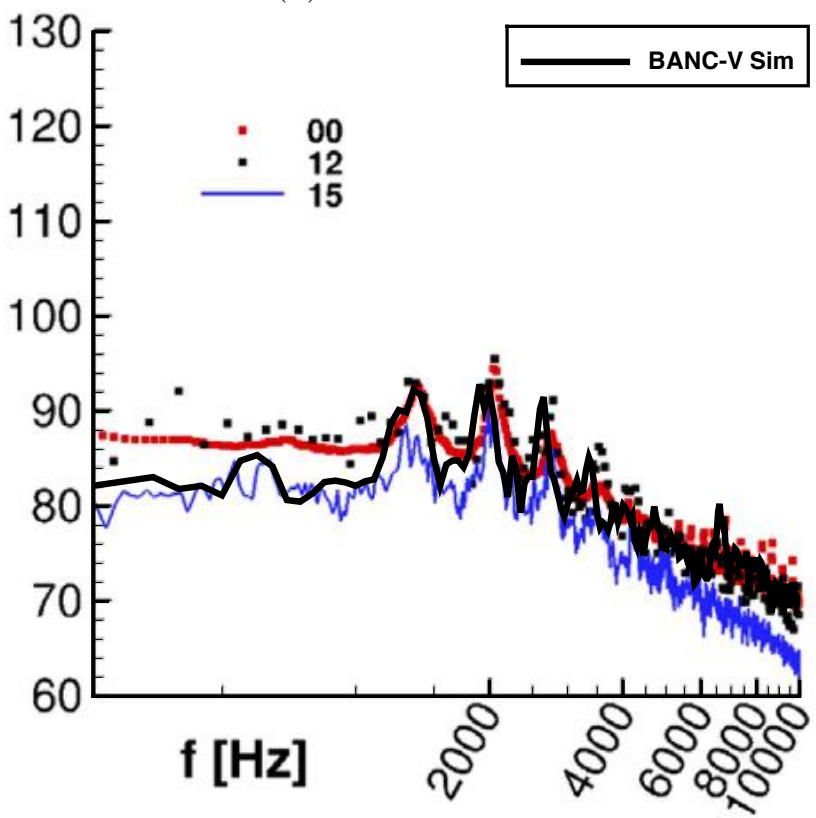

(d) Point sensor 6

Figure 12. (a) Diagram of PSD sensor locations on the 30P30N slat and leading edge of the main-element. Comparison of PSD spectrum with previous workshop participants from BANC-III including experimental results (square symbols) at (b) point sensors 1 , (c) point sensor 4, and (d) point sensor 6. 


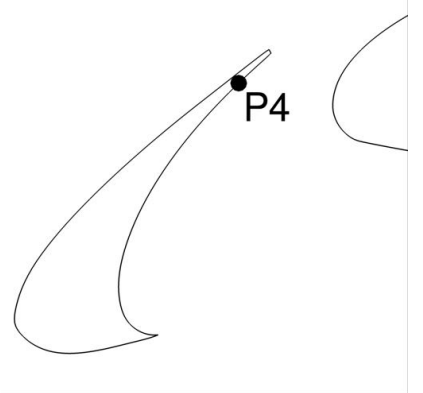

(a)

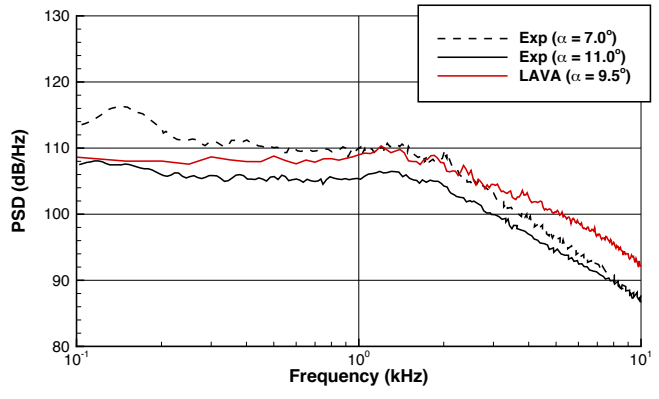

(c)

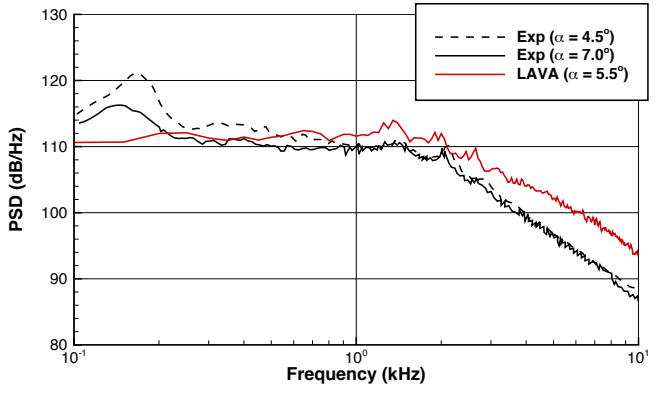

(b)

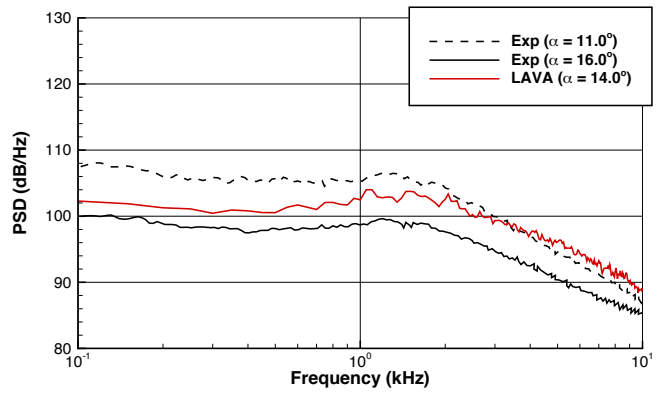

(d)

Figure 13. Comparison of PSD spectrum from zonal hybrid RANS-LES simulations with LWT2-Kevlar wall wind tunnel data at (a) sensor location 4 , (b) $\alpha=5.5$ degrees, (c) $\alpha=9.5$, and (d) $\alpha=14.0$.

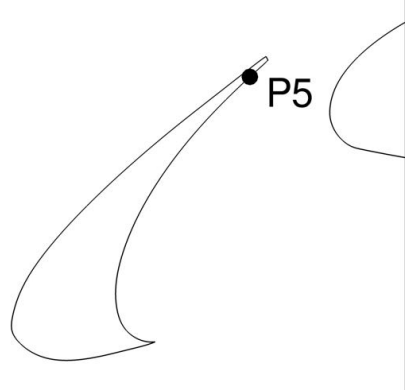

(a)

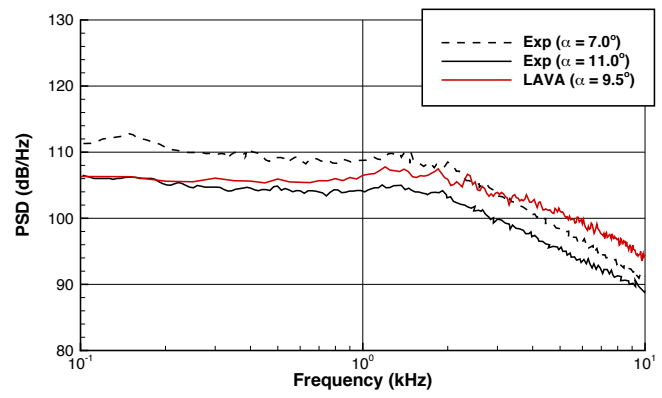

(c)

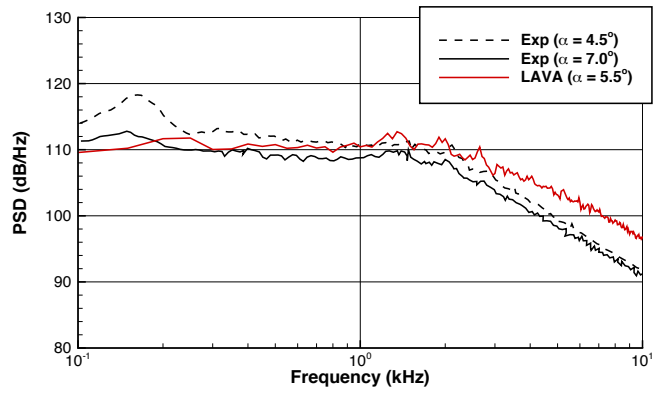

(b)

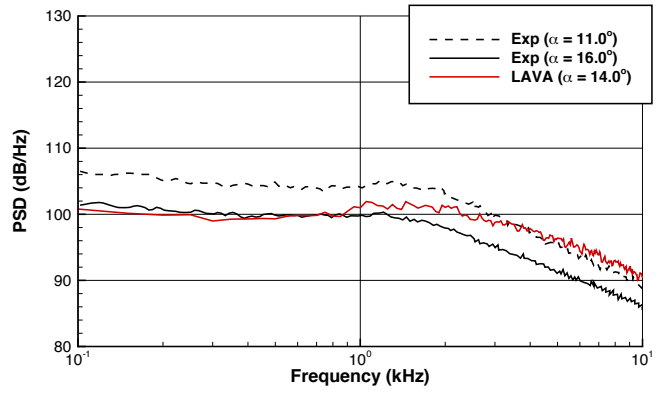

(d)

Figure 14. Comparison of PSD spectrum from zonal hybrid RANS-LES simulations with LWT2-Kevlar wall wind tunnel data at (a) sensor location 5 , (b) $\alpha=5.5$ degrees, (c) $\alpha=9.5$, and (d) $\alpha=14.0$. 


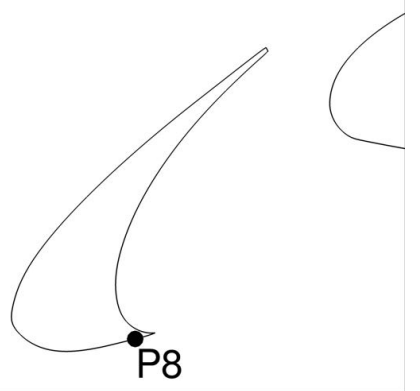

(a)

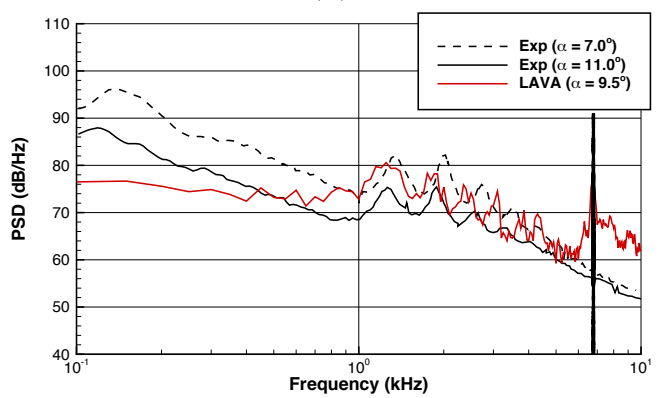

(c)

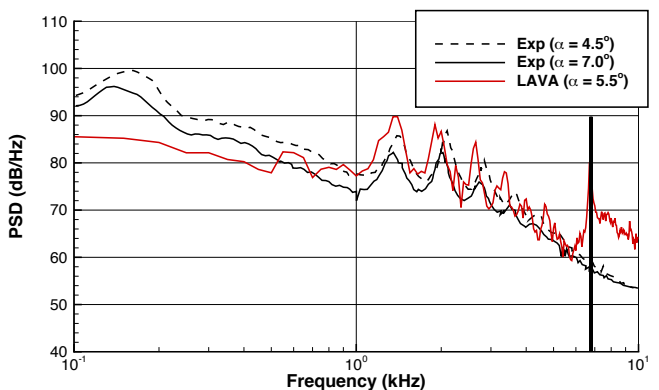

(b)

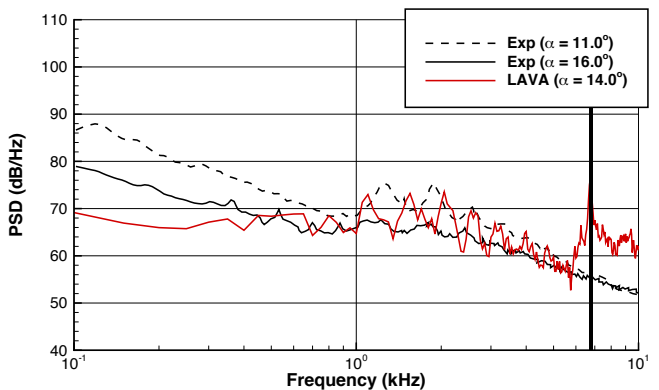

(d)

Figure 15. Comparison of PSD spectrum from zonal hybrid RANS-LES simulations with LWT2-Kevlar wall wind tunnel data at (a) sensor location 8, (b) $\alpha=5.5$ degrees, (c) $\alpha=9.5$, and (d) $\alpha=14.0$. Note a thick vertical line is added at $6785 \mathrm{~Hz}$ to identify the spurious frequency associated with the span width of the computational domain.

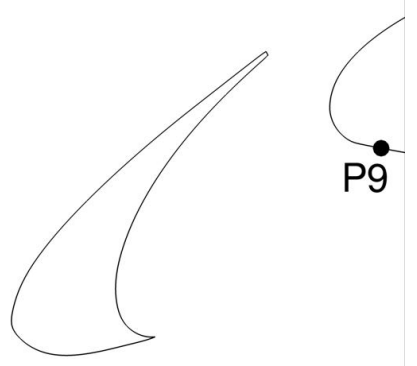

(a)

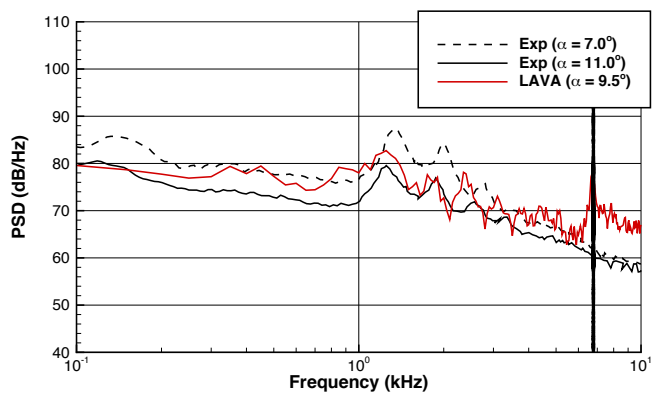

(c)

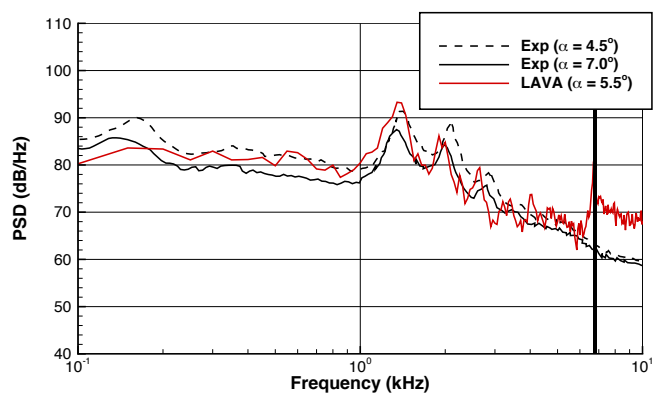

(b)

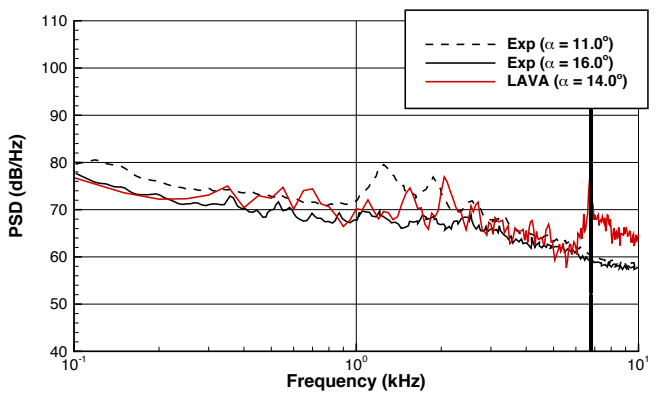

(d)

Figure 16. Comparison of PSD spectrum from zonal hybrid RANS-LES simulations with LWT2-Kevlar wall wind tunnel data at (a) sensor location 9, (b) $\alpha=5.5$ degrees, (c) $\alpha=9.5$, and (d) $\alpha=14.0$. Note a thick vertical line is added at $6785 \mathrm{~Hz}$ to identify the spurious frequency associated with the span width of the computational domain. 


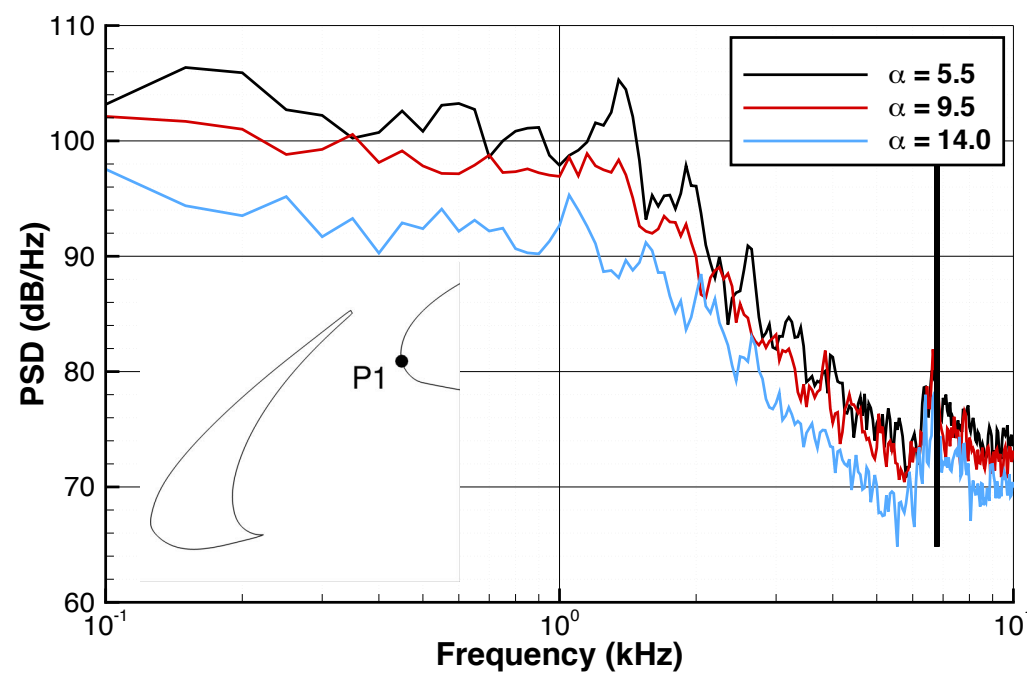

(a) Point sensor 1

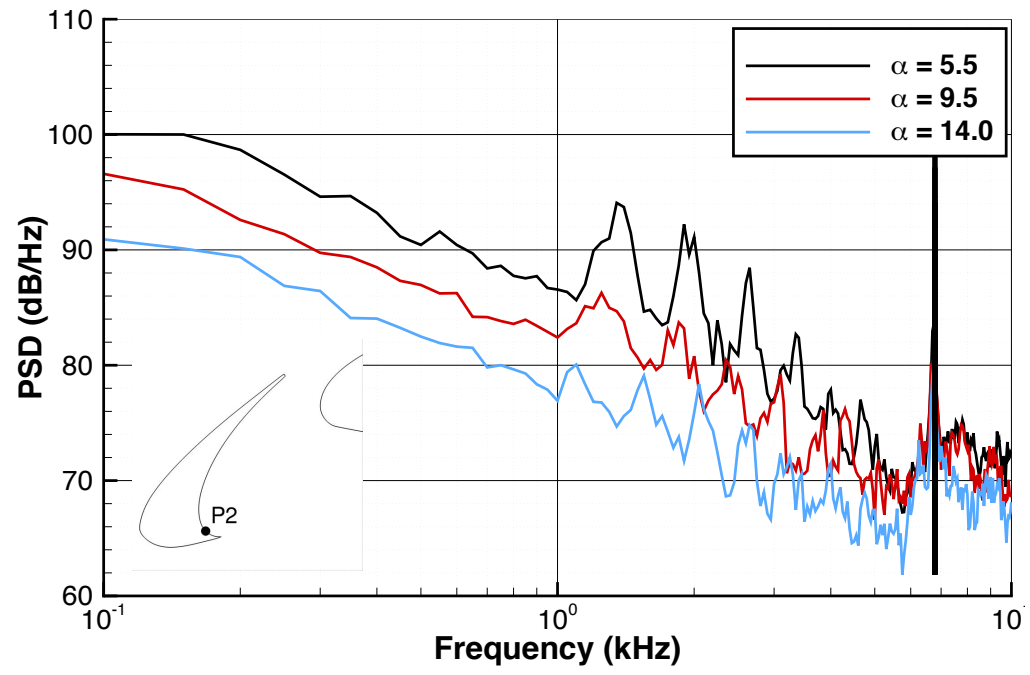

(b) Point sensor 2

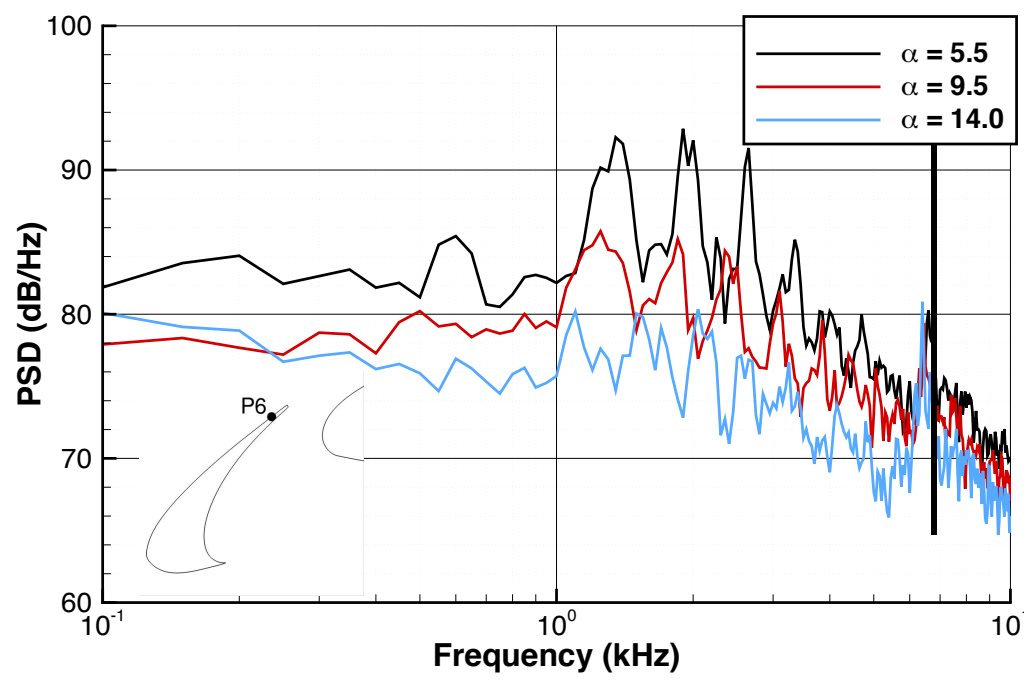

(c) Point sensor 6

Figure 17. PSD spectrum from zonal hybrid RANS-LES simulations plotted for each angle of attack at (a) sensor location 1, (b) sensor location 2, and (c) sensor location 6. 

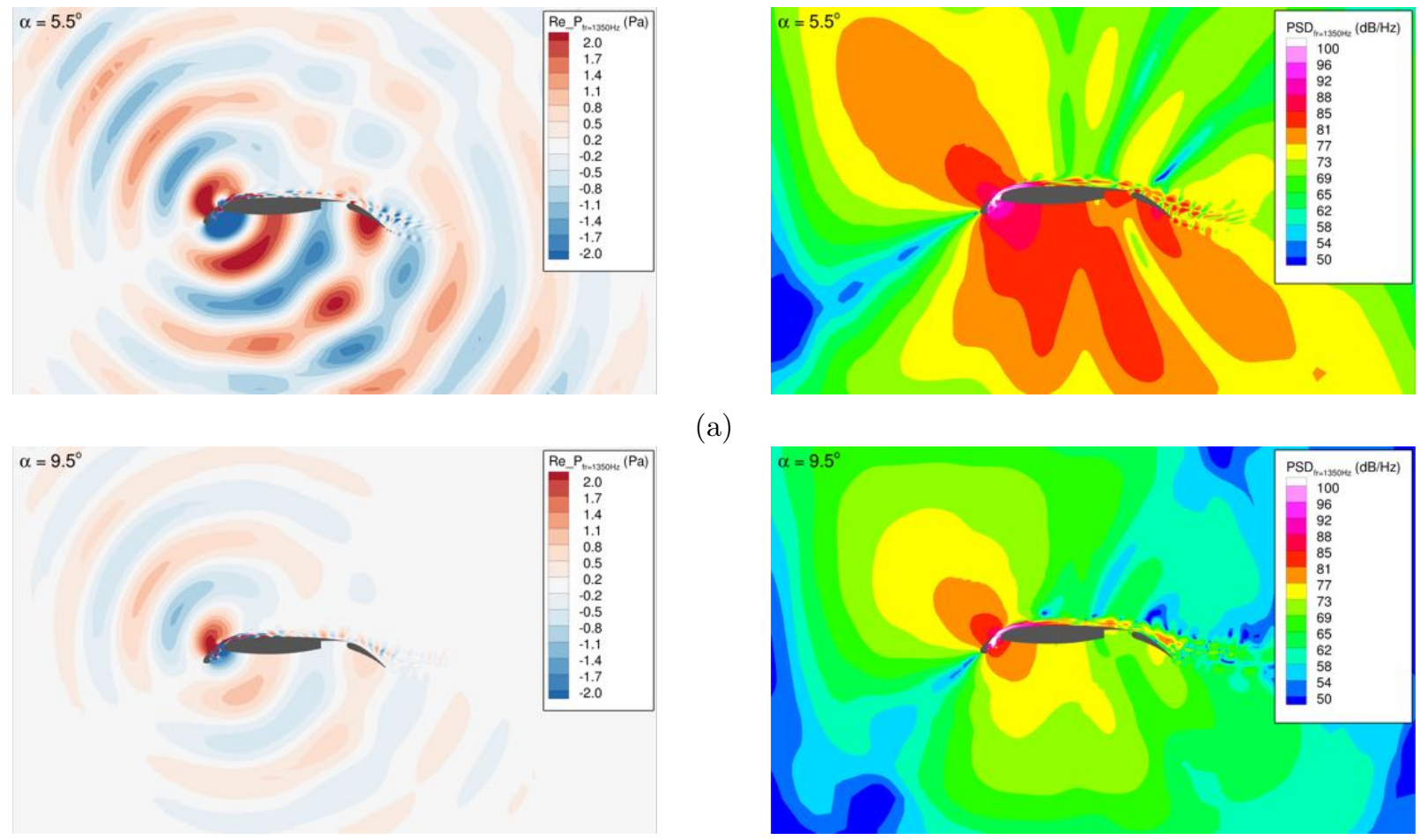

(a)

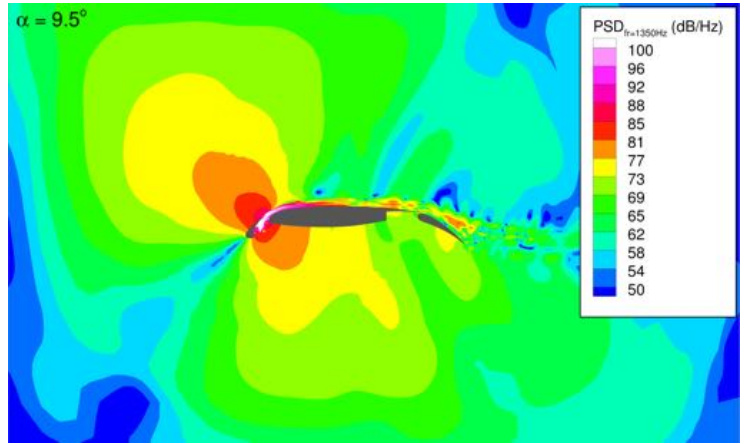

(b)
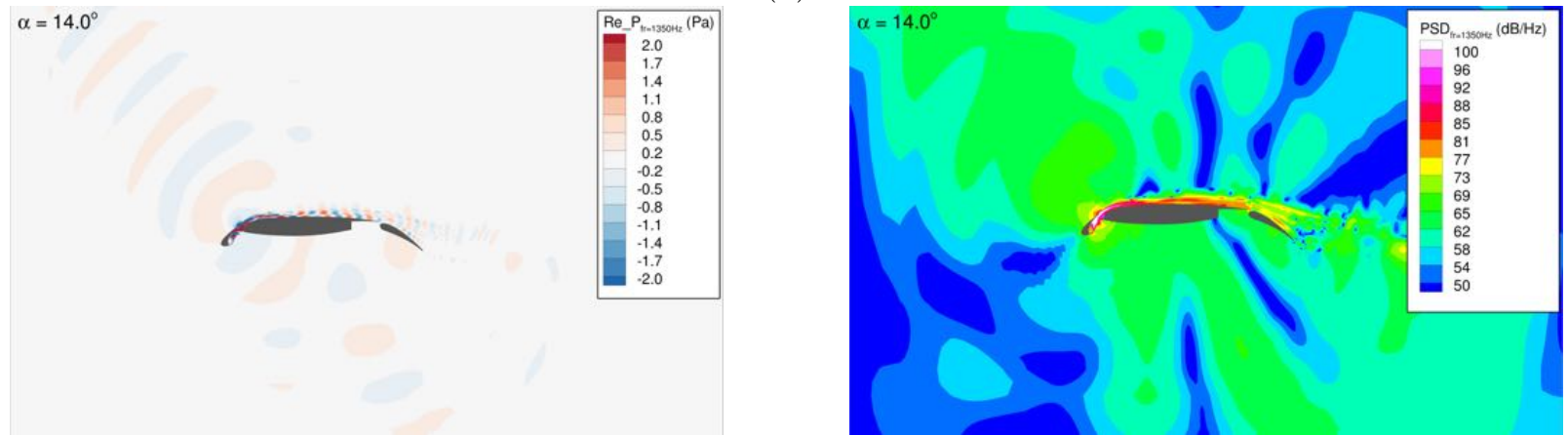

(c)

Figure 18. Comparison of real-part of Fourier coefficient of pressure (left) and PSD (right) at the first narrow-band peak $1350 \mathrm{~Hz}$ for (a) $\alpha=5.5$ degrees, (b) $\alpha=9.5$ degrees, (c) $\alpha=14.0$ degrees. 

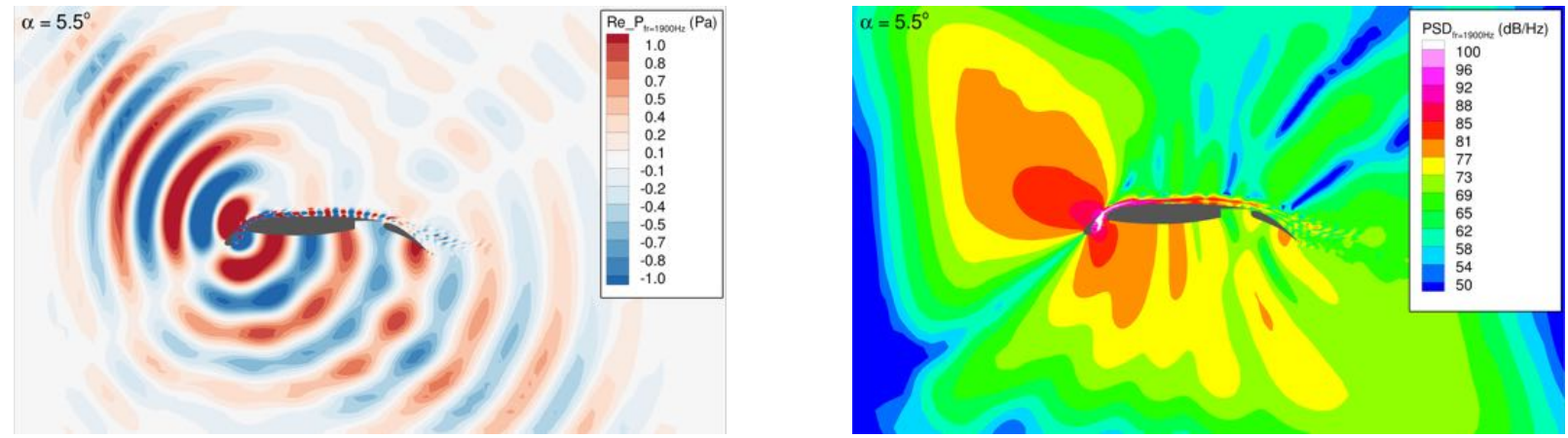

(a)
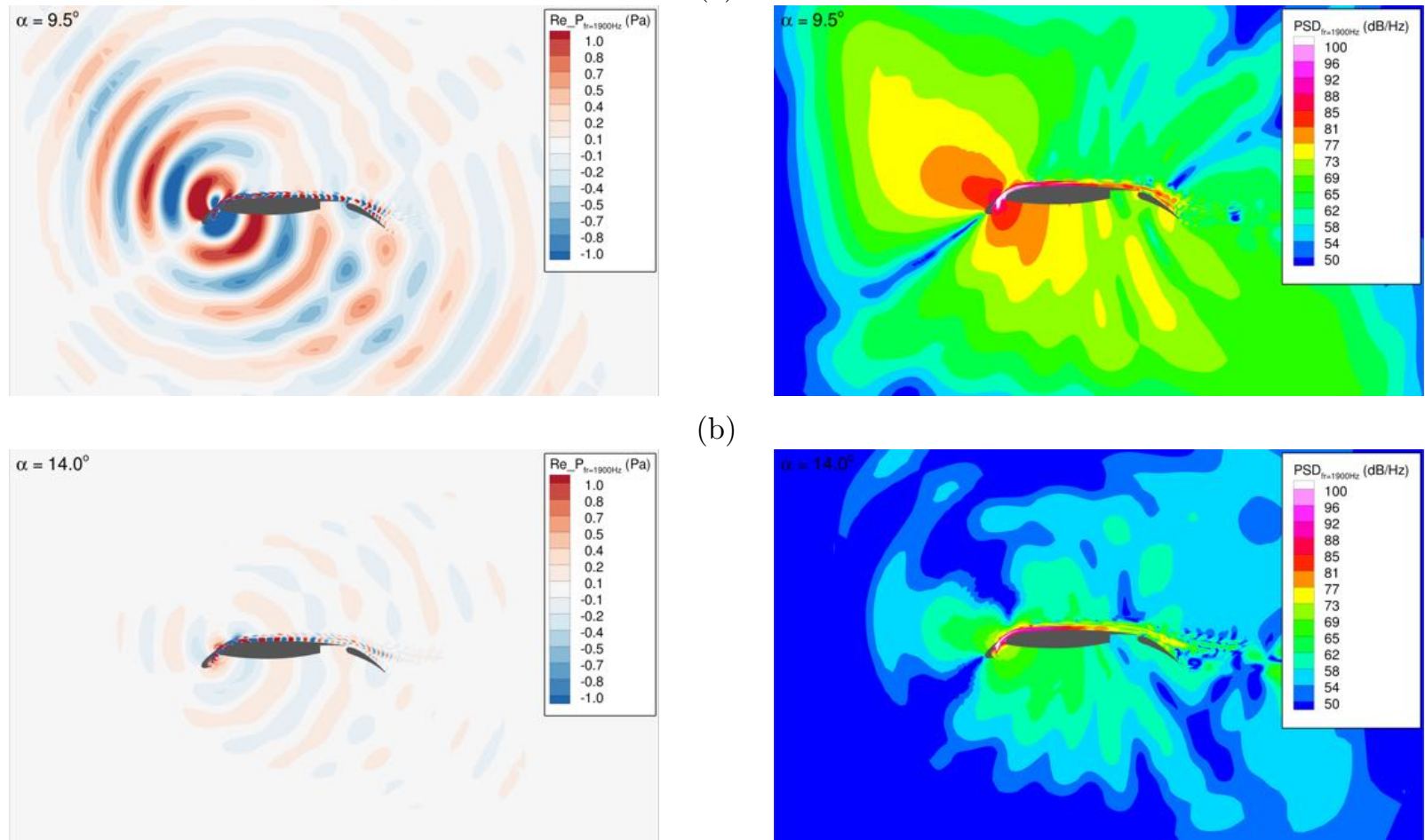

(b)

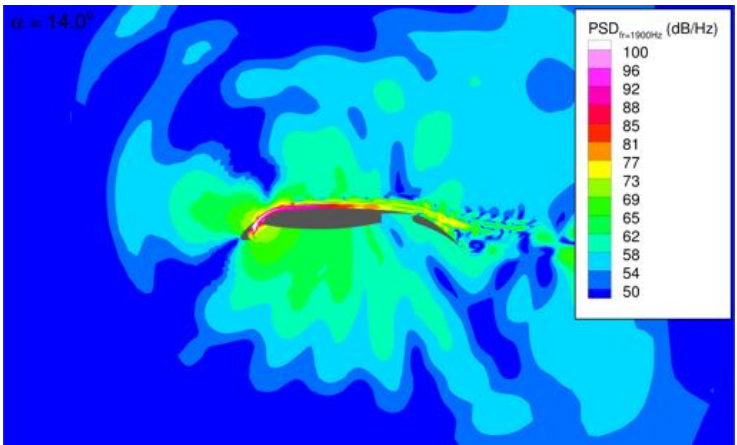

(c)

Figure 19. Comparison of real-part of Fourier coefficient of pressure (left) and PSD (right) at the second narrow-band peak $1900 \mathrm{~Hz}$ for (a) $\alpha=5.5$ degrees, (b) $\alpha=9.5$ degrees, (c) $\alpha=14.0$ degrees. 


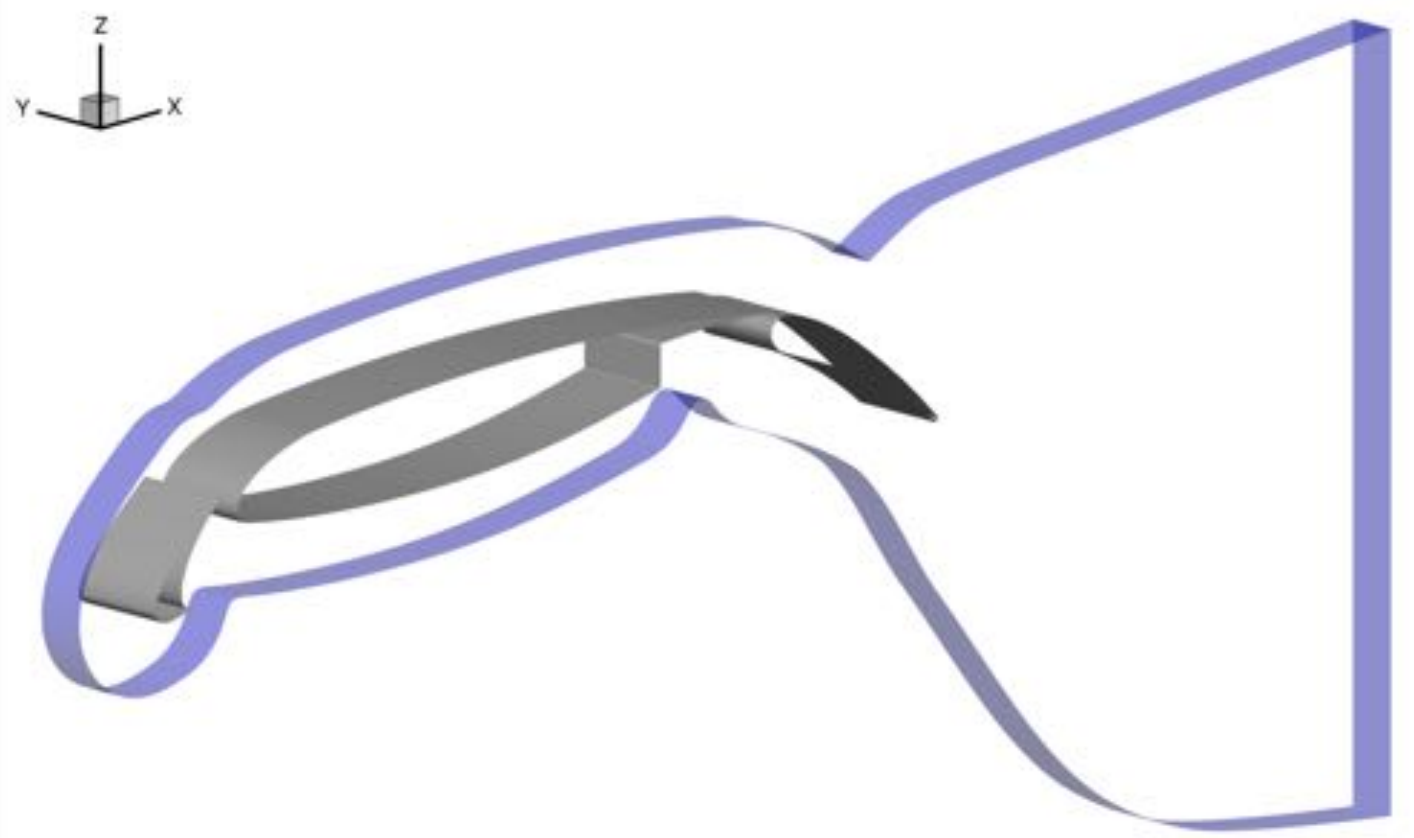

Figure 20. Ffowcs Williams-Hawkings (FWH) acoustic surface (transparent blue) plotted along with the 30P30N surface geometry.

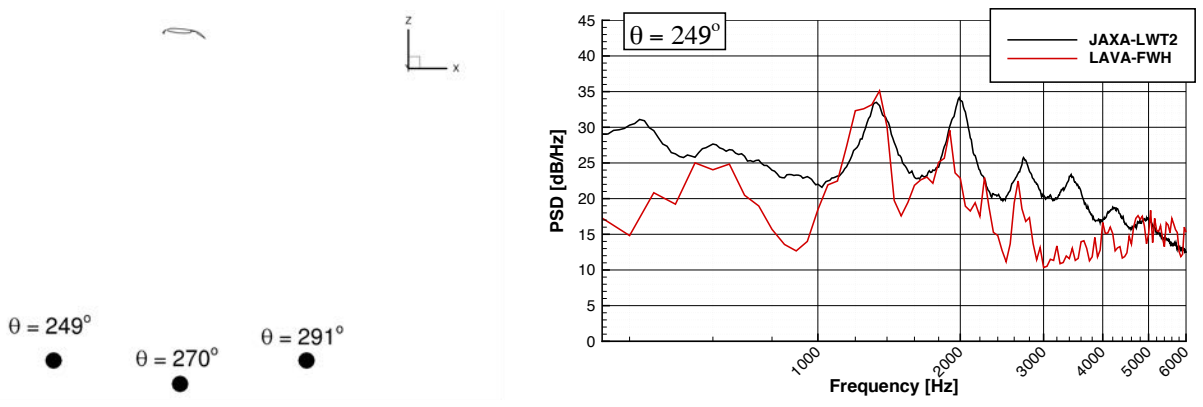

(a) Diagram $\alpha=5.5$ degrees

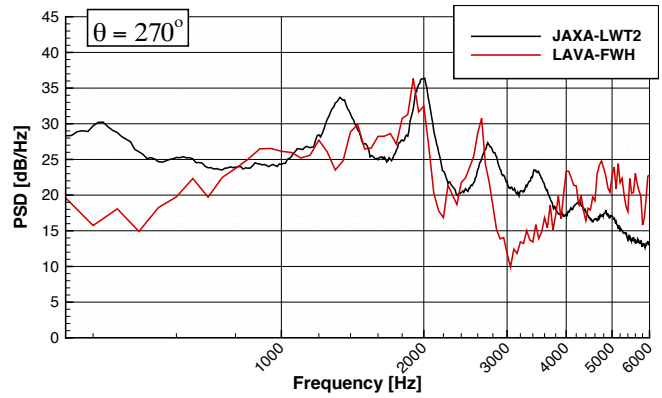

(c) $\theta=270$ degrees (b) $\theta=249$ degrees

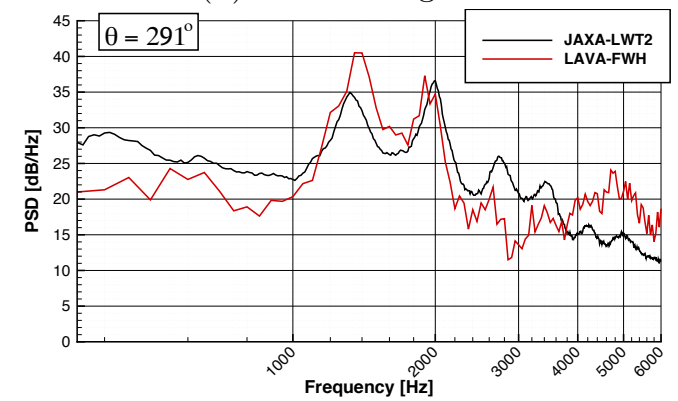

(b) $\theta=291$ degrees

Figure 21. (a) Diagram of far-field (10c) observer locations for $\alpha=5.5$ degrees. Comparison of far-field PSD spectrum from zonal hybrid RANS-LES with LWT2-Kevlar wall wind tunnel data for $\alpha=5.5$ degrees at (a) observer angle $\theta=249$ degrees, (b) observer angle $\theta=270$ degrees, and (c) observer angle $\theta=291$ degrees. 

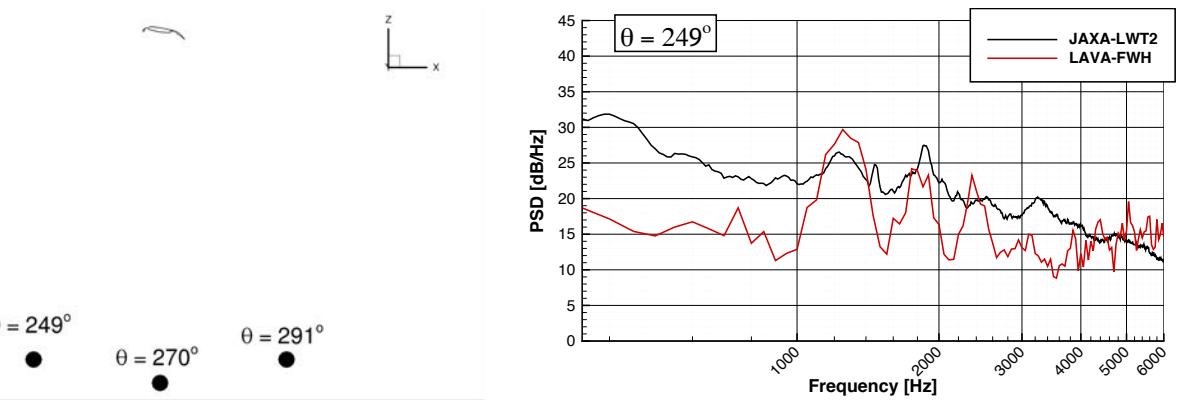

(a) Diagram $\alpha=9.5$ degrees

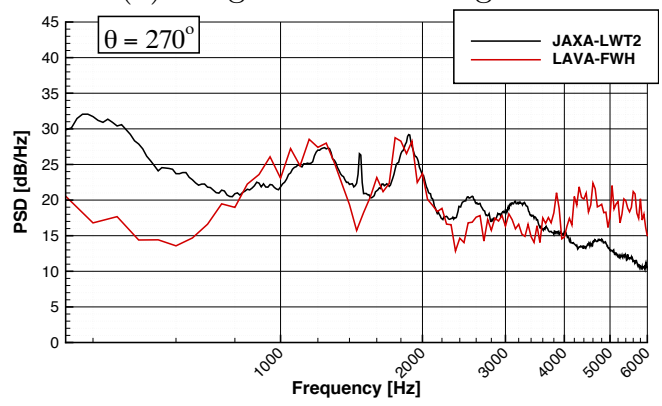

(c) $\theta=270$ degrees

(b) $\theta=249$ degrees

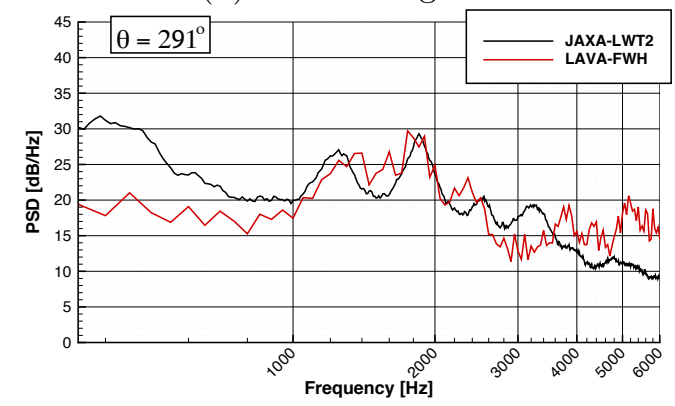

(b) $\theta=291$ degrees

Figure 22. (a) Diagram of far-field (10c) observer locations for $\alpha=9.5$ degrees. Comparison of far-field PSD spectrum from zonal hybrid RANS-LES with LWT2-Kevlar wall wind tunnel data for $\alpha=9.5$ degrees at (a) observer angle $\theta=249$ degrees, (b) observer angle $\theta=270$ degrees, and (c) observer angle $\theta=291$ degrees.

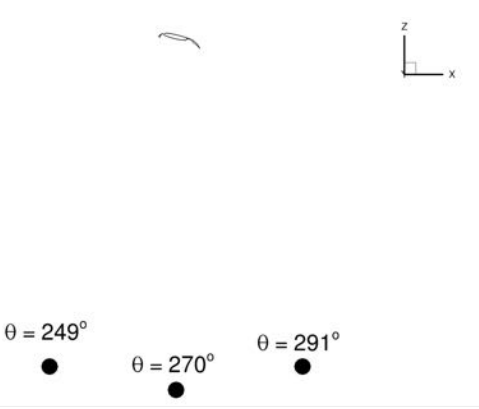

(a) Diagram $\alpha=14.0$ degrees

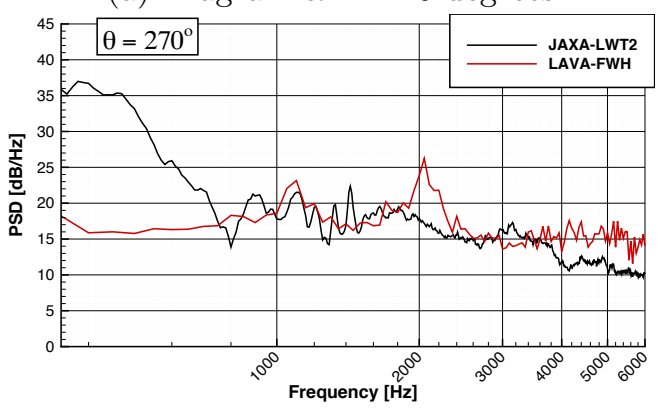

(c) $\theta=270$ degrees

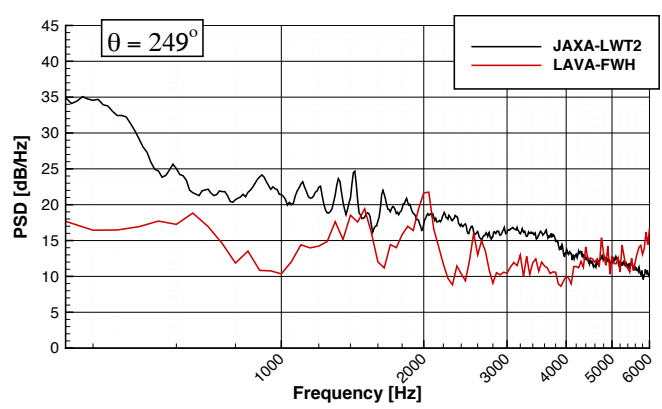

(b) $\theta=249$ degrees

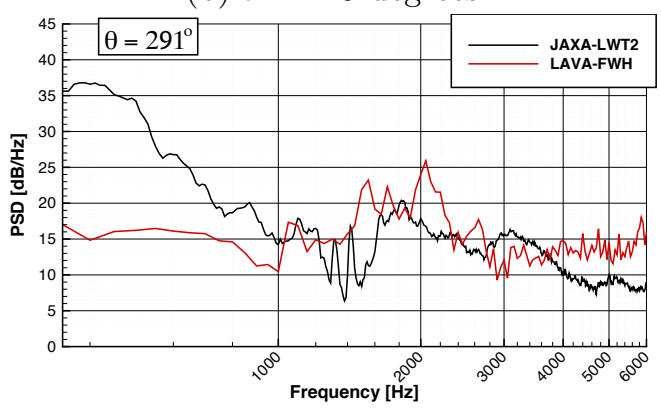

(b) $\theta=291$ degrees

Figure 23. (a) Diagram of far-field (10c) observer locations for $\alpha=14.0$ degrees. Comparison of far-field PSD spectrum from zonal hybrid RANS-LES with LWT2-Kevlar wall wind tunnel data for $\alpha=14.0$ degrees at (a) observer angle $\theta=249$ degrees, (b) observer angle $\theta=270$ degrees, and (c) observer angle $\theta=291$ degrees. 


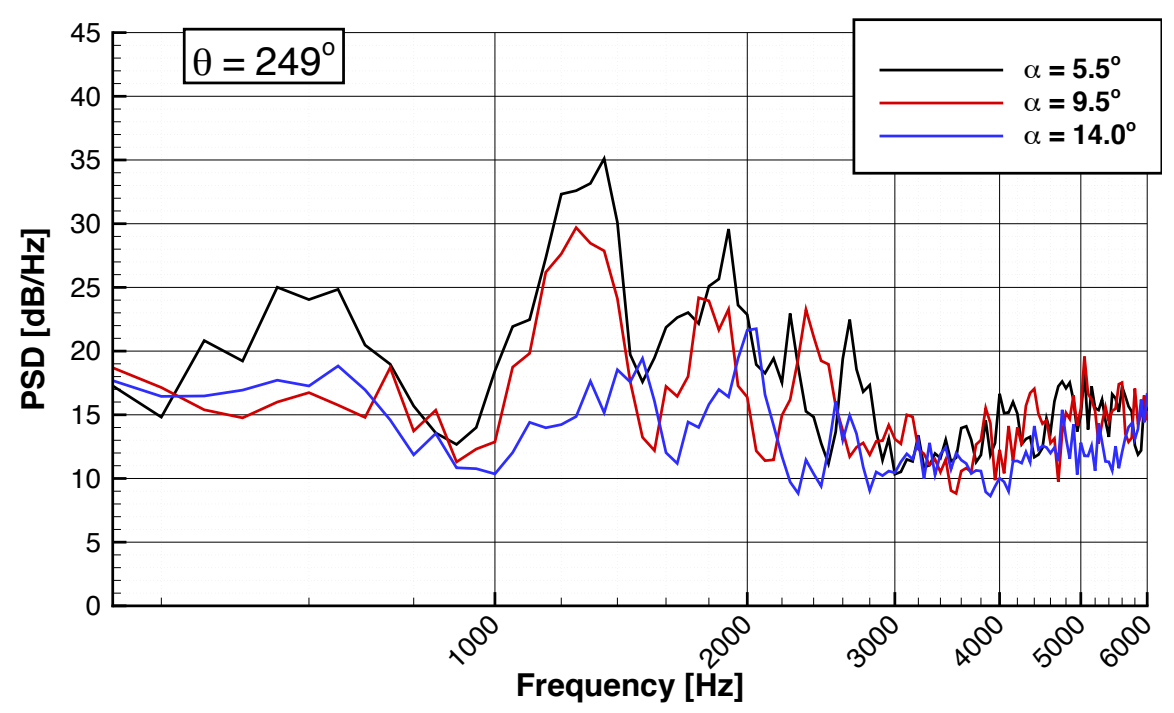

(a) $\theta=249$ degrees

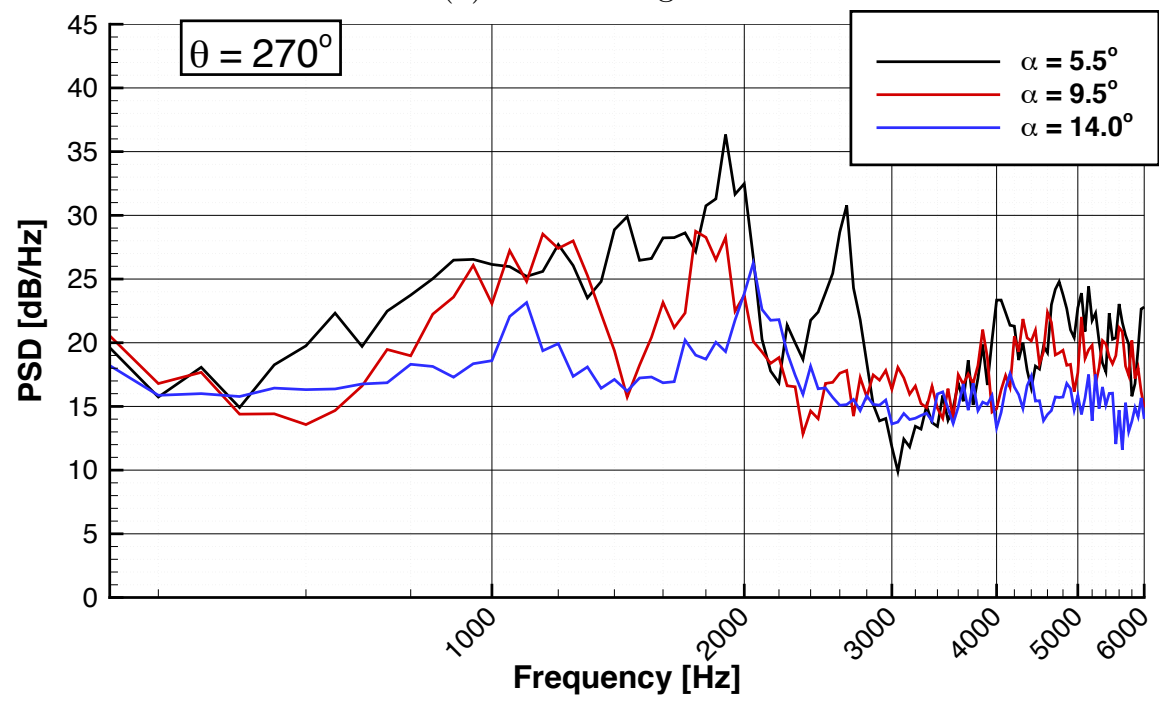

(b) $\theta=270$ degrees

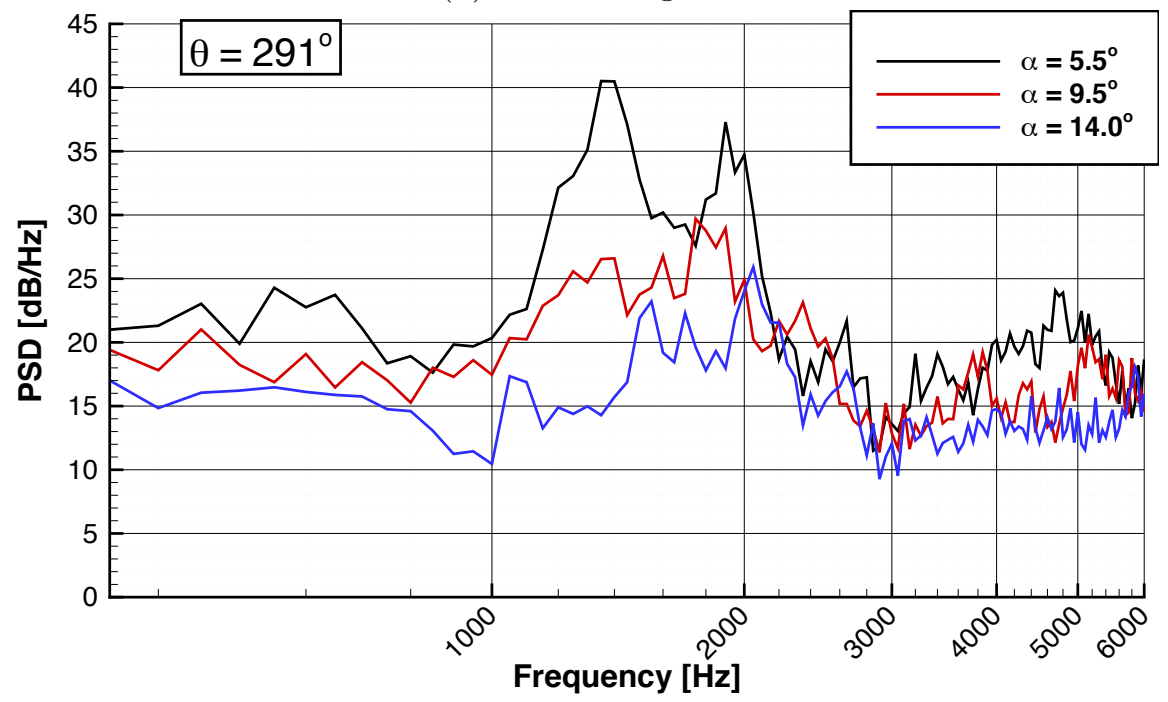

(c) $\theta=291$ degrees

Figure 24. Far-field PSD spectrum using zonal hybrid RANS-LES for each angle of attack, $\alpha=5.5,9.5$, and 14.0 degrees at (a) observer angle $\theta=249$ degrees, (b) observer angle $\theta=270$ degrees, and (c) observer angle $\theta=291$ degrees. 


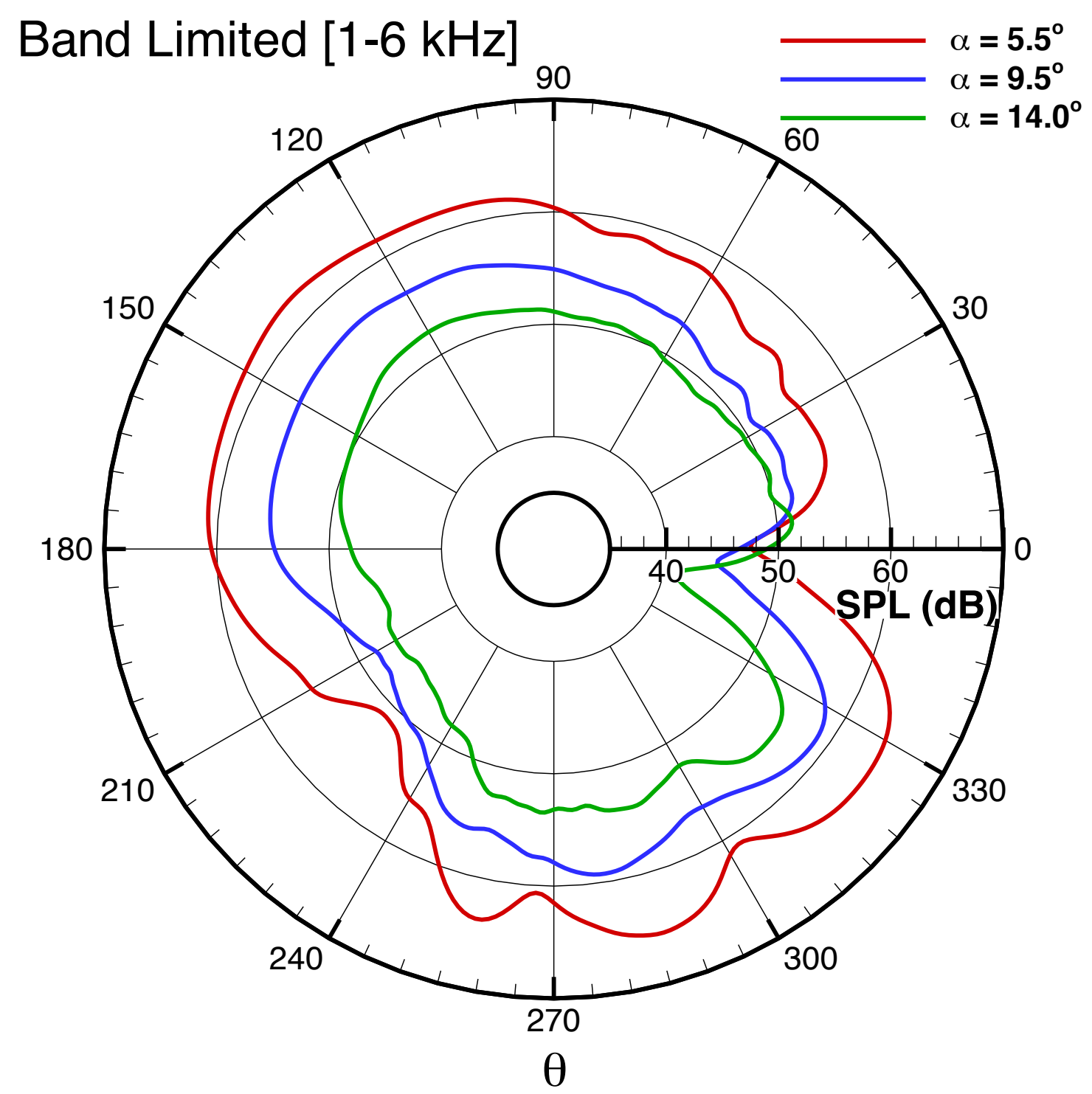

Figure 25. Band-limited OASPL $([1-6] \mathrm{kHz})$ directivity plot comparing each angle of attack. Note axis is centered around $0.4 \mathrm{c}$ to be consistent with JAXA wind tunnel comparisons reported above. 